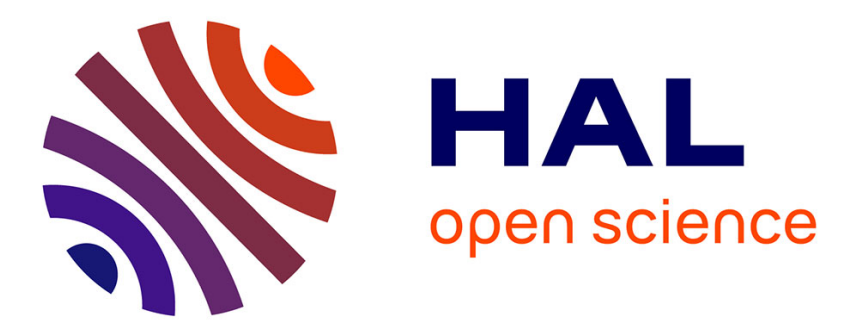

\title{
The Xanthate Route to Indolines, Indoles, and their Aza Congeners
}

Samir Z Zard

\section{To cite this version:}

Samir Z Zard. The Xanthate Route to Indolines, Indoles, and their Aza Congeners. Chemistry - A

European Journal, 2020, 26 (56), pp.12689-12705. 10.1002/chem.202001341 . hal-03416856

\section{HAL Id: hal-03416856 \\ https://hal.science/hal-03416856}

Submitted on 5 Nov 2021

HAL is a multi-disciplinary open access archive for the deposit and dissemination of scientific research documents, whether they are published or not. The documents may come from teaching and research institutions in France or abroad, or from public or private research centers.
L'archive ouverte pluridisciplinaire HAL, est destinée au dépôt et à la diffusion de documents scientifiques de niveau recherche, publiés ou non, émanant des établissements d'enseignement et de recherche français ou étrangers, des laboratoires publics ou privés. 


\section{The Xanthate Route to Indolines, Indoles, and their Aza}

\section{Congeners}

\section{Samir Z. Zard ${ }^{*[a]}$}

Dedicated with respect to the memory of Professor Rolf Huisgen, a chemistry hero to many.

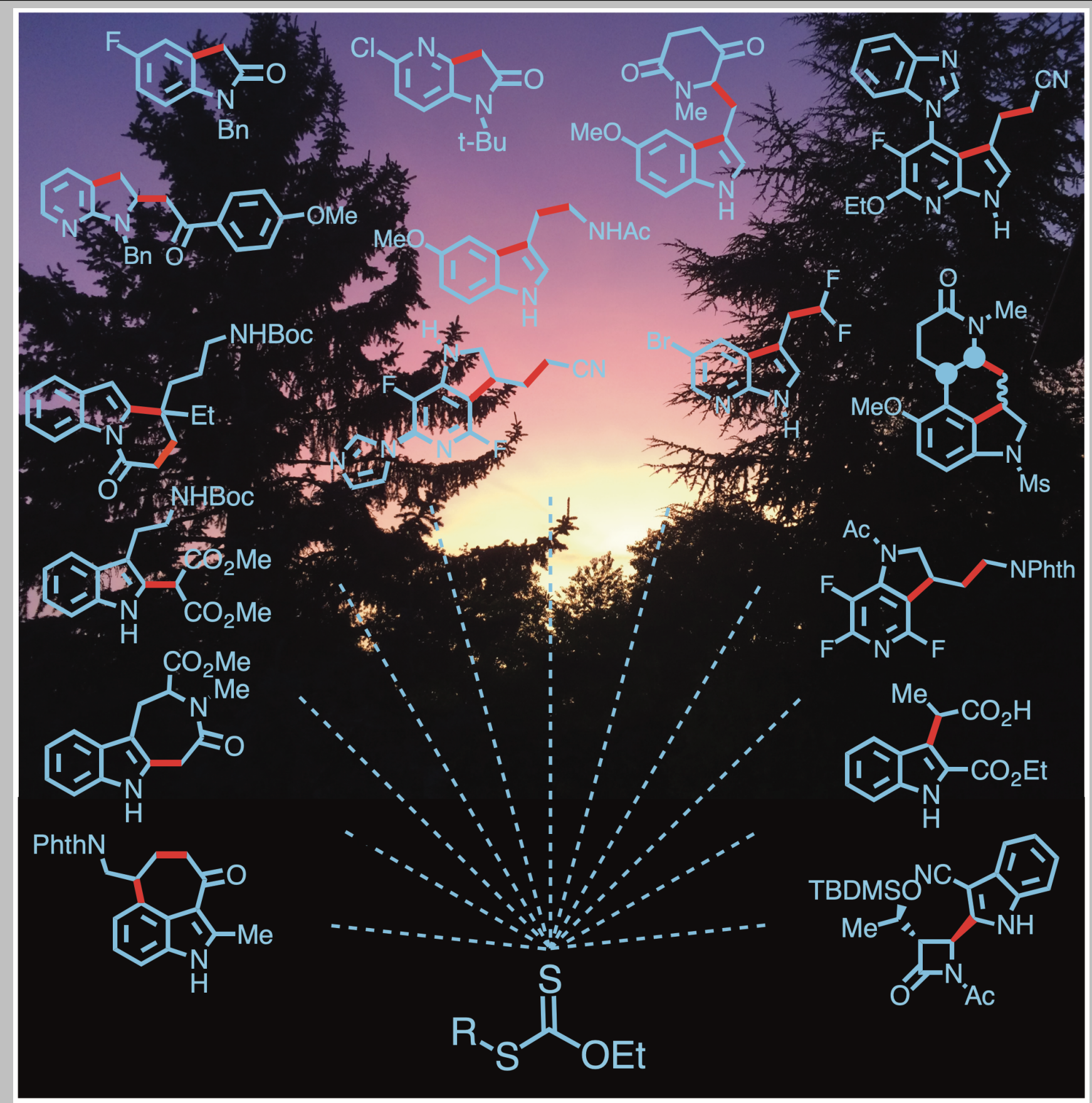


Text for frontispiece: Intermolecular radical addition of xanthates followed by radical cyclisation to aromatic or heteroaromatic rings allows the convergent and modular synthesis of myriad indolines, indoles, and their aza analogues under mild conditions. The tolerance for polar functional groups and the introduction of fluorinated motifs are particularly noteworthy. This chemistry can be applied to the simplified synthesis of alkaloids and medicinally relevant structures.

[a] Prof. Dr. S. Z. Zard

Laboratoire de Synthèse Organique, UMR 7652

Ecole Polytechnique

91128 Palaiseau, France

E-mail: samir.zard@polytechnique.edu

\begin{abstract}
Convergent routes to a variety of indolines, indoles, oxindoles, and their aza analogues involving radical additions of xanthates are described. Three approaches are summarized. The first is the least general and relies on the generation of aryl or heteroaryl radicals starting from diazonium salts. The second involves radical addition to $\mathrm{N}$-allylanilines followed by ring-closure onto the aromatic core. A large variety of indolines and azaindolines can thus be obtained and, in many cases, converted into the corresponding indoles and azaindoles by various methods. The synthesis of novel fluoroazaindolines and fluoroazaindoles by a rare homolytic ipsosubstitution of fluorine atoms is particularly noteworthy. The last approach hinges on the direct modification of indoles by radical addition to the pyrrole subunit of the indole nucleus. Application of this methodology to the total synthesis of melatonin and the alkaloids mersicarpine, caulerpine, and the pentacyclic skeleton of tronocarpine is briefly discussed. Most of the compounds described herein would be difficult to obtain by more traditional routes.
\end{abstract}

can therefore lead to a broader diversity of structures. The price to pay is the possible formation of regioisomers, depending on the nature and position of the substituents on the aromatic ring, since the ring-closure leading to the 5-membered ring portion of the indole can in principle take place on either side of the aniline nitrogen. The last category consists of methods allowing the modification of existing indoles. Numerous ionic, organometallic, and radical processes have been used to this end. ${ }^{[1,6]}$ Xanthates can be used in all three categories. They complement earlier methods and allow the synthesis of a broad diversity of indolines and indoles, oxindoles, as well as their aza analogues which are gaining importance in medicinal and plant protection chemistry. ${ }^{[7]}$

\section{Mechanism of the Xanthate Addition to Alkenes}

Biographical Sketch. Samir Z. Zard was born in 1955 in Ife, Nigeria. His training as a chemist started at the American University of Beirut, then at Imperial College, London, and finally at the Université Paris-Sud, Orsay, France, where he received his doctorate under the supervision of Professor Sir Derek Barton in 1983. His main research concerns the study and development of new reactions and processes, with a special interest in radicals, organosulfur derivatives,

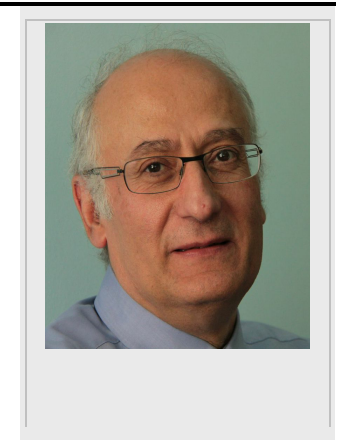
indoles, indolines, and their aza analogues, relying on the unique radical chemistry of dithiocarbonates (xanthates) will be briefly described.

It would be a futile task to attempt to provide a digestible summary of the immense literature related to the synthesis of indoles and indolines. Suffice it to say that the various routes can be roughly divided into three categories, and that indoles and indolines can generally be interconverted, so that access to one family can be construed as a potential entry into the other. The first category starts with ortho-substituted anilines or their precursors, such as nitrobenzenes. Several textbook named reactions fall into this class: the Batcho-Leimburger, Reissert, Madelung, Hegedus, and Larock syntheses. ${ }^{[1,4]}$ The second category encompasses approaches starting with anilines or their precursors without the need for an extra functionalization in the ortho-position. In this class one finds the great Fischer indole synthesis and its more modern variants, ${ }^{[5]}$ as well as the Gassman, Bartoli, and Nenitzescu reactions, the last starting with a benzoquinone. ${ }^{[1,4]}$ These reactions offer the advantage of simpler and more accessible starting materials than those of the first category and alkynes, and nitro compounds. In addition to a number of academic awards, he received in 2007 the Croix de Chevalier de la Légion d'Honneur.

The radical addition of xanthates to alkenes embodies a number of unique features that need to be briefly explained. The key element is the ability of xanthates and their congeners to reversibly store reactive radicals in a dormant form. This enhances significantly their lifetime, even in a concentrated medium, while simultaneously regulating their absolute and relative concentrations. ${ }^{[8]}$ This remarkable property can be readily understood by studying the simplified mechanistic manifold outlined in Scheme 1. 
WILEY-VCH

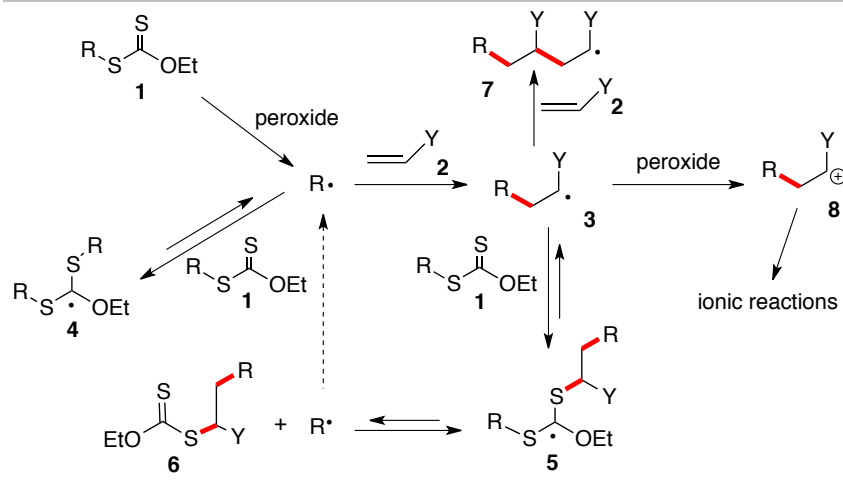

Scheme 1. Mechanistic Manifold for the Addition of Xanthates to Alkenes.

Radical $\mathbf{R} \cdot$ derived from xanthate $\mathbf{1}$ following an initiation step is rapidly captured by another xanthate molecule to give adduct 4 . This reaction is fast, reversible and degenerate. This new radical is stabilised by three heteroatoms, it is too bulky to couple rapidly with other radicals, and is unable to undergo disporportionation because it bears no $\beta$-hydrogens. Its main reaction channel is to fragment back to $R \cdot$. The continuous regeneration of starting radical $R \cdot$ increases considerably its effective lifetime, allowing it to react even with electronically unbiased alkene 2 . Adduct radical 3 is in turn reversibly intercepted by xanthate 1 and the resulting adduct $\mathbf{5}$ is likewise a dormant species. The absolute steady state concentration of radicals $R \cdot$ and $\mathbf{3}$ remains extremely low because the equilibrium favors the generally more stabilized adduct radicals $\mathbf{4}$ and $\mathbf{5}$. Active radicals $R \cdot$ and $\mathbf{3}$ are hence reversibly stored in an inactive dormant state most of the time. As a consequence, unwanted radical-radical interactions are significantly curtailed.

Furthermore, the fast equilibration between radicals $R \cdot$ and 3 (through intermediate 5) makes it possible to modulate their relative concentration by a judicious choice of the reacting partners, so as to discourage the formation of oligomers 7 and favor instead the pathway leading to product $\mathbf{6}$. This is usually accomplished by selecting radical $R \cdot$ in such a way that it is more stable than adduct radical $\mathbf{3}$. The collapse of intermediate $\mathbf{5}$ will therefore proceed more easily towards the former. In this simple analysis, polar factors have been neglected even though they can play an important role.

In cases where adduct radical $\mathbf{3}$ is stabilized by an electrondonating group, it is possible to use the peroxide to oxidize it into cation 8. This crossover from the radical to the cationic manifold has proved exceedingly valuable for the synthesis of indolines, indoles, oxindoles, and myriad other (hetero)aromatic derivatives. There are many more subtle aspects to this process. Interested readers will find more detailed mechanistic discussions in the reviews listed in ref.9. ${ }^{[9]}$

From a preparative standpoint, this technology offers a number of decisive advantages, namely: very inexpensive (bulk price 2 to 5 USD per kg!) and non-toxic reagents; easily scalable and safe experimental procedures; the ability to operate at high concentration and in many cases even without a solvent; and, last but not least, a broad compatibility with many functional groups, especially polar functions that are often problematic with other chemistries. More than 2000 additions have been described so far, pitting numerous alkenes against hundreds of xanthates bearing a wide variety of functional groups. This brief review summarizes novel routes to indolines, indoles, oxindoles, and their aza congeners devised using this powerful chemistry.

\section{Indolines by Radical Cyclization}

\subsection{Cyclizations Starting with Aromatic Radicals}

Most of the previous radical based pathways to indolines involve the cyclization of aryl radicals 10 onto a tethered alkene to furnish adduct 11 (Scheme 2). Substituent $X$ in precursor 9 is most frequently a bromine, an iodine, or a diazonium salt, and the corresponding radical $\mathbf{1 0}$ can be generated using a variety of reagents: stannanes, silanes, hypophosphorus salts, transition metal salts and complexes, etc. ${ }^{[10]}$ By contrast, producing aryl radicals directly from xanthates is problematic. The reason lies in the difficult fragmentation of adducts such as $\mathbf{4}$ and $\mathbf{5}$ in Scheme 1 , when high energy aryl radicals have to be created $\left(R^{\bullet}=A r^{\bullet}\right)$. There is however an indirect route to aryl radicals via diazonium salts. ${ }^{[11]}$ This contrivance is illustrated starting from aniline 12. Diazotization followed by addition of potassium O-ethyl xanthate gives rise to diazenyl xanthate 13. Laboratory lighting is sufficient to initiate a highly efficient chain reaction, whereby diazinyl radical 14 is formed followed by loss of molecular nitrogen, ring-closure of aryl radical 15, and, finally, transfer of the xanthate group by reaction of the cyclized radical with diazenyl xanthate 13 . The overall sequence affords indoline 16. Five indolines 17-21 were prepared in the same manner, the last being an example of an azaindoline.
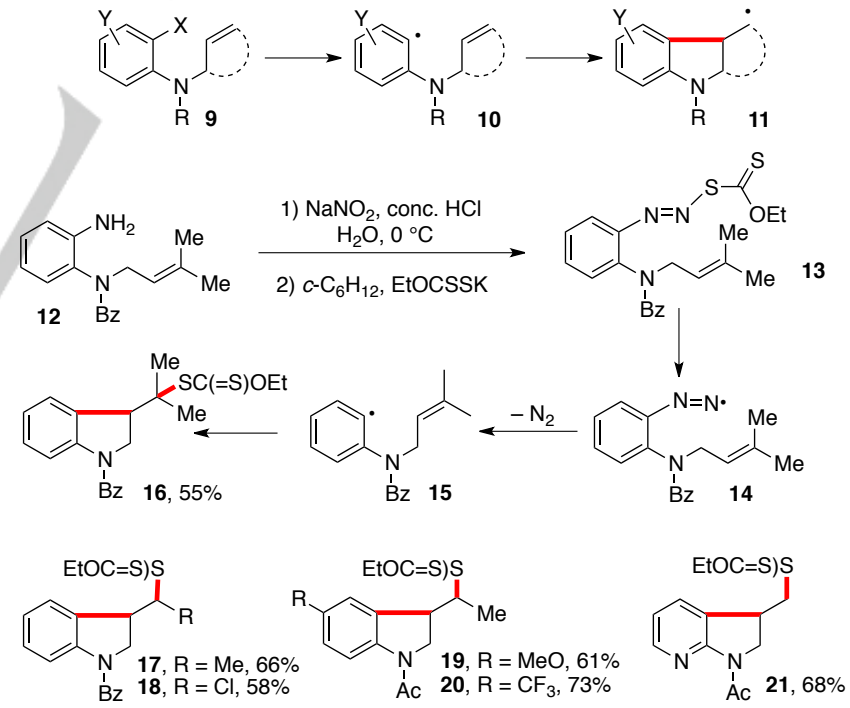

Scheme 2. Indolines and Azaindolines from Diazonium Salts.

It is important to add an organic solvent, cyclohexane in this case, before the gradual addition of the xanthate salt. The diazenyl xanthate $\mathbf{1 3}$ dissolves in the organic layer as it is formed and does not separate from the aqueous diazotization medium. This avoids triggering an exothermic chain reaction in the neat material, which could lead to an explosion, especially if the diazenyl xanthate separates as a liquid. This is the only case where handling xanthates could pose a safety hazard due to fast propagation 
steps and the uncontrollable liberation of molecular nitrogen. Prior addition of an organic solvent and the portion-wise incorporation of the xanthate salt dilutes the diazenyl xanthate and makes the process safe and easily controllable and scalable. Such precautions are not necessary with the transformations discussed hereafter.

\subsection{Radical Cyclizations onto Aromatic Rings}

The above route to indolines and azaindolines suffers from the same drawback as for previously described methods, namely the need for ortho functionalized aromatic precursors. In the present case, the ortho amino group is necessary for the formation of the requisite diazonium salt. Despite this limitation, most radical based methods have adopted this strategy because the rate constant for the 5-exo cyclisation of an aromatic radical $\mathbf{1 0}$ is exceedingly high $\left(k>10^{7} \mathrm{~s}^{-1}\right)^{[12]}$ and can easily compete with other pathways open to the radical, such as premature hydrogen atom abstraction from the reagent (e. g. $\left.\mathrm{Bu}_{3} \mathrm{SnH}\right)$ or the solvent. The alternative mode whereby an alkyl radical closes onto an aromatic or heteroaromatic ring is less easily implemented because it is a much slower and, in many cases, a reversible process (see $\mathbf{2 4} \boldsymbol{\mathbf { 2 }} \mathbf{2 5}$ in Scheme 3). Thus, a study by Gansäuer, Grimme, and co-workers has determined a rate constant for the cyclisation of approximately $10^{3} \mathrm{~s}^{-1}$, which is several orders of magnitude smaller than that for the $\mathbf{1 0} \rightarrow \mathbf{1 1}$ step. ${ }^{[13]}$ aniline 22, both of which can bear a variety of different functional groups. The potential for generating diversity is therefore immense. The examples collected in Scheme 4 provide a glimpse of the possibilities. ${ }^{[14-21]}$ The structure of intermediate adducts 23a-p is not shown, but the yields for the addition step are given.
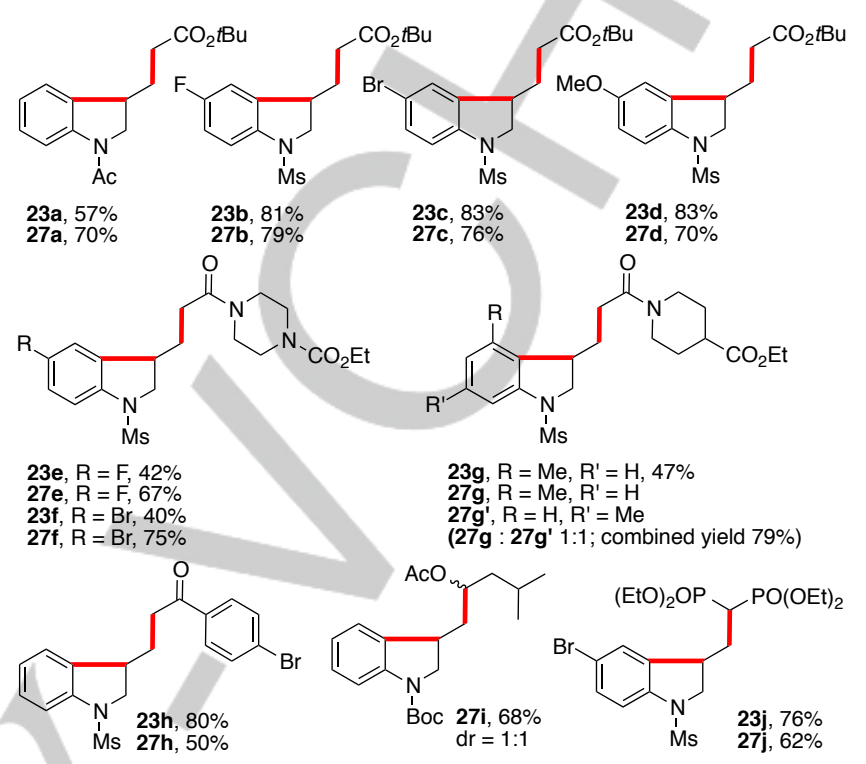

23g, $R=M e, R^{\prime}=H, 47 \%$

27g, $R=M e, R^{\prime}=H$

$27 \mathbf{g}^{\prime}, R=H, R^{\prime}=M$

27g: 27g' 1:1; combined yield $79 \%$

27f, $\mathrm{R}=\mathrm{Br}, 75 \%$

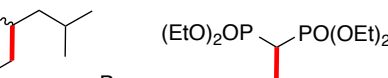
$27 \mathbf{i}, 68 \%$<smiles>CCCC1CN(C)c2ccc(Br)cc21</smiles><smiles>[R5]C(S)C(=O)OCC</smiles>

$$
\underbrace{\mathrm{R}^{\prime}}_{23}
$$<smiles>[H][R]1c2ccccc2c2ccccc12</smiles>

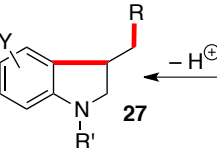

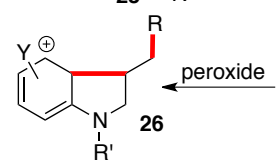<smiles>[2H]C[C@H]1CNC2=CC=[Y]CC21</smiles>
$R^{\prime} 24$

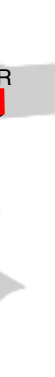

Scheme 3. General Mechanistic Scheme for Indoline Formation.

The relatively long lifetime of radicals produced by the xanthate method, as discussed above, can be exploited to overcome this kinetic barrier and, in association with the ability to accomplish intermolecular additions to un-activated alkenes, opens up vast possibilities for the synthesis of indolines and indoles. The conception underlying this approach is outlined in Scheme 3. Readily accessible $\mathrm{N}$-allyl anilines $\mathbf{2 2}$ are used as the alkene partners in the radical addition with xanthate 1 . The resulting adduct $\mathbf{2 3}$ is then subjected to the action of a stoichiometric amount of the peroxide. This operation regenerates intermediate radical $\mathbf{2 4}$ under conditions where the only trap (apart from the solvent) is the aromatic ring. The ring closure furnishes stabilized cyclohexadienyl radical 25 , which can be oxidized into the corresponding cation $\mathbf{2 6}$ by an electron transfer to the peroxide. Loss of a proton finally gives the desired indoline 27 .

In this process, the peroxide is used both as an initiator and as a stoichiometric oxidant. It is worthwhile pointing out that this transformation can be viewed as the synthetic equivalent of an intramolecular Friedel-Crafts reaction, performed under neutral, non-acidic and metal-free conditions. The final indoline $\mathbf{2 7}$ derives in a modular fashion from two components, xanthate 1 and $\mathrm{N}$-allyl

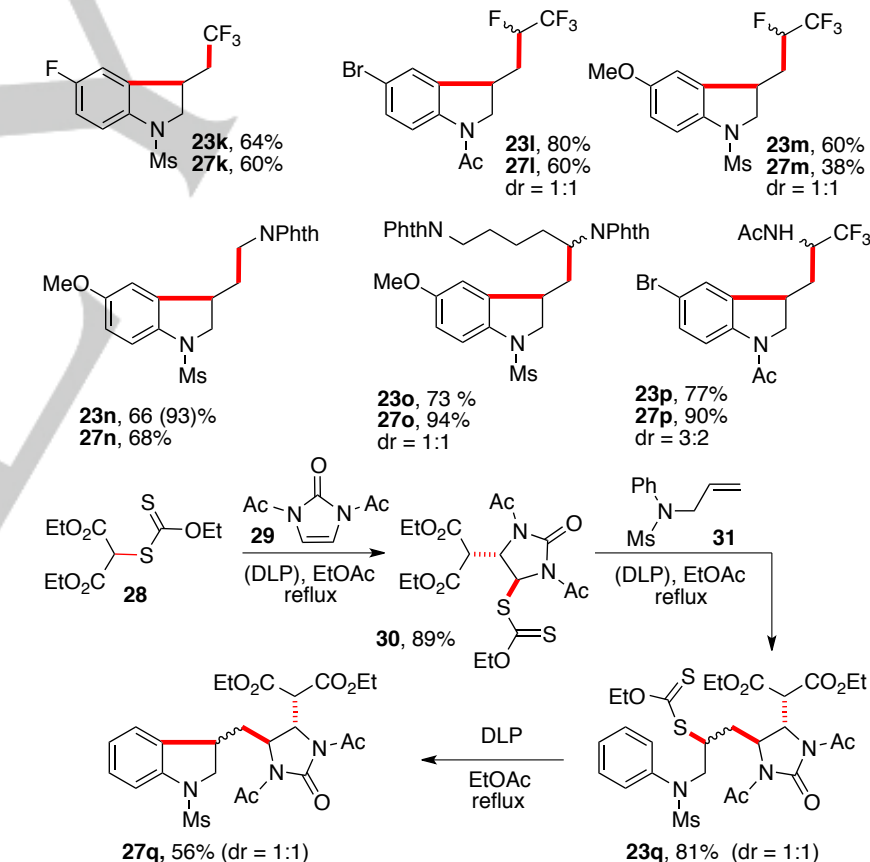

Scheme 4. Convergent Syntheses of Indolines.

Throughout this review, the yields in parenthesis (e. g., for 23n) correspond to yields based on recovered starting material. The xanthate partner can contain various groups: ester (27a-d), amide $(\mathbf{2 7 e - g})$, ketone $(\mathbf{2 7 h}),{ }^{[14]}$ acetoxy $(\mathbf{2 7 i}),{ }^{[15]}$ bis-phosphonate $(\mathbf{2 7 j}),{ }^{[16]}$ trifluoromethyl $(\mathbf{2 7 k}),{ }^{[17]}$ tetrafluoroethyl $(\mathbf{2 7}, \mathbf{m}),{ }^{[18]}$ protected amine $\left(\mathbf{2 7 n}\right.$; Nphth $=$ phthalimide), ${ }^{[19]}$ protected diamine (27o), ${ }^{[20]}$ and $\alpha$-trifluoromethyl acetamide (27p), ${ }^{[21]}$ Notice that the yield of adducts 23, arising from an intermolecular radical addition to an unactivated alkene, are generally higher than the actual 
intramolecular step leading to indolines $\mathbf{2 7}$. When the substituent on the aromatic ring is in the meta position as in $\mathbf{2 3 g}$, the cyclization leads to a mixture of two regioisomers $\mathbf{2 4} \mathbf{g}$ and $\mathbf{2 4} \mathbf{g}$ ' in comparable yield. The lack of regioselectivity when two possible cyclization sites are available is the main shortcoming of this approach, similarly to methods of the second category (e. g., Fischer indole synthesis) discussed in the introduction.

Xanthate chemistry also allows in some instances a threecomponent construction of highly complex indolines. One sequence is displayed in the lower part of Scheme 4. It involves the first addition of malonyl xanthate 28 to imidazolinone $\mathbf{2 9}$ to give adduct 30 , followed by a subsequent addition to allylaniline 31 and cyclization of resulting xanthate $\mathbf{2 3 q}$ to furnish indoline 27q. ${ }^{[22]}$ DLP is the acronym for Di-Lauroyl Peroxide (also sold as lauroyl peroxide, or Laurox ${ }^{\circledR}$ or Luperox $\operatorname{LP}^{\circledR}$ ). DLP is placed in parentheses in the first and second steps to indicate that it is used as an initiator, whereas it is used in stoichiometric amounts in the third step (no parentheses).

Modification of the initial indolines constitutes another springboard to access structural diversity. Some examples are provided in Scheme 5 . Indoline $\mathbf{2 7 r}$ can thus be converted into dithiane 32 and thence into aldehyde 33 using standard reactions. ${ }^{[23]}$ Alternatively, desulfurization with Raney nickel affords ethyl indoline 34 . The overall sequence in this case corresponds to the addition-cyclization of a methyl radical, which cannot be done directly because methyl radicals are not stabilized and are difficult to generate cleanly using this xanthate chemistry (cf. the case of aryl radicals discussed in section 3.1).<smiles>CCCCCC1CN(C)c2ccccc21</smiles>

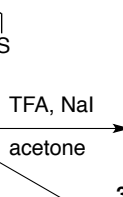<smiles>c1ccc2c(c1)NCC2CC1CCCS1</smiles>
Mel, $\mathrm{CH}_{2} \mathrm{Cl}_{2}$

$33,51 \%$ Ác $23 r, 75 \%$
$27 r, 69 \%$ W2 Ra-Ni<smiles>CC(C)C1CN(C)c2ccccc21</smiles><smiles></smiles>
$\mathbf{2 3 s}, 88 \% \stackrel{\text { Ms }}{27 s}, 73 \%(\mathrm{dr}=1.1: 1)$
(1)

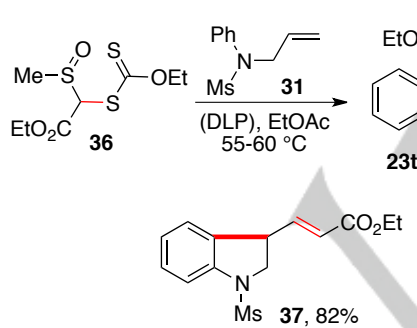
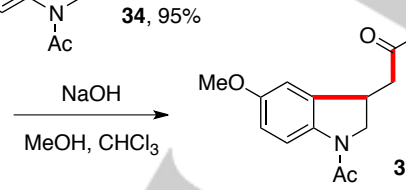

(1)
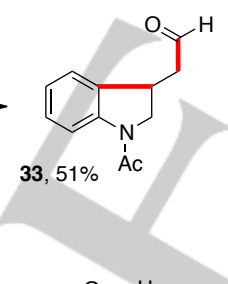<smiles>C1CCCC1</smiles>
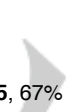
side-chain of the indolines opens another venue for the construction of molecular architectures of increased complexity through an alliance with the Friedel-Crafts reaction. Several examples are pictured in Scheme $7 .{ }^{[28]}$ In the first two, gentle heating of acetals $27 y$ and $\mathbf{2 7 z}$ with $p$-toluenesulfonic acid in toluene gives rise to tricyclic structures 45 and $\mathbf{4 6}$ respectively. Not unexpectedly, the presence of an electron-donating methoxy group in the latter example increases the efficiency of the electrophilic aromatic substitution.

The synthesis of trifluoromethyl-substituted tricyclic indoline $\mathbf{4 7}$ illustrates both the ease of accessing trifluoromethyl ketones such as precursor 23aa by addition of the a trifluoroacetonyl xanthate to alkenes ${ }^{[29]}$ and the ability, more generally, of preparing fluorinated compounds. ${ }^{[30]}$

Higher polycyclic indolines can be obtained by starting with adducts derived from cyclic ketonyl xanthates. Tetracyclic indoline 48 prepared from cyclohexanone $27 \mathrm{ab}$ is a representative example. ${ }^{[28]}$ The synthesis of indoline 50, which can be viewed as an analogue of lysergic acid, does not rely on a Friedel-Crafts based cyclisation but on a radical ring closure of thiocabonyl imidazolide 49 proceeding under mild conditions. ${ }^{[28]}$ 
This transformation was inspired by an earlier observation by Minisci and co-workers, who reported the radical addition of a Barton-McCombie type xanthate onto protonated pyridines and quinolines. ${ }^{[31]}$

$$
\begin{aligned}
& \text { 23y, } \mathrm{R}=\mathrm{R}^{\prime}, \mathrm{R}^{\prime}=\mathrm{COCF}_{3}, 97 \% \\
& \text { 27y, } \mathrm{R}=\mathrm{H}, \mathrm{R}^{\prime}=\mathrm{COCF}_{3}, 61 \% \\
& \text { 23z, } \mathrm{R}=\mathrm{OMe}, \mathrm{R}^{\prime}=\mathrm{Ms}^{\prime}, 96 \% \\
& \text { 27z, } \mathrm{R}=\mathrm{OMe}, \mathrm{R}^{\prime}=\mathrm{Ms}, 47 \%
\end{aligned}
$$

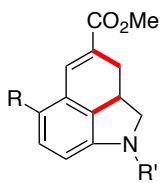

45, $\mathrm{R}=\mathrm{H}, \mathrm{R}^{\prime}=\mathrm{COCF}_{3}, 40 \%$ 46, $R=O M e, R^{\prime}=M s, 70 \%$

$$
{ }_{\substack{\text { Ms } \\ \text { Msaa, } 58 \%}}^{\text {23aa, } 65 \%}
$$

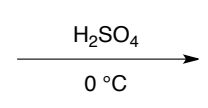

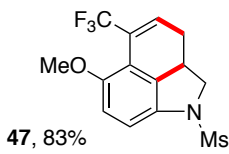<smiles>COc1ccc2c(c1)C(CC1CCCCC1=O)CN2</smiles><smiles>CC(C)C(=O)OCc1ccccc1</smiles>
Ms $\begin{aligned} & 23 a b, 65 \% \\ & 27 a b, 66 \%\end{aligned}$ $0{ }^{\circ} \mathrm{C}$<smiles>COc1ccc2c3c1CC1C=S2N(C)CC3C1</smiles><smiles>COc1ccc2c(c1)C(CC1C(=O)CCC(=O)N1C)CN2[N+](=O)[O-]</smiles>
$48,45 \%$

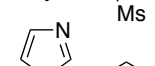

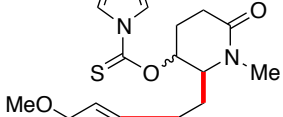

DCE, $\mathrm{r}$

23ac, $73 \%$
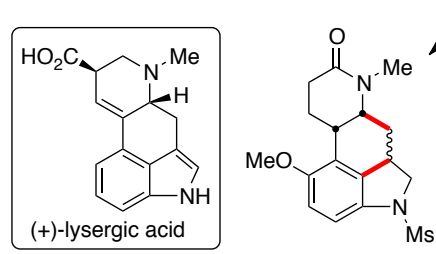

Scheme 7. Synthesis of Tricyclic and Tetracyclic Indolines.

\subsection{Cyclizations onto Pyridines and Pyrimidines}

Classical methods for synthesis of indolines and indoles do not readily extend to their aza congeners. Ortho substituted aminopyridines are less accessible, and the powerful Fischer indole synthesis requires harsh conditions and often proceeds poorly and sometimes completely fails with pyridyl hydrazones. ${ }^{[2]}$ The xanthate-based approach does not suffer from such limitations. The intermolecular xanthate addition to $\mathrm{N}$-allyl aminopyridines $\mathbf{5 1}$ and the subsequent ring closure of adduct $\mathbf{5 2}$ to give azaindolines 53 take place normally (Scheme 8 ). The main requirement is the need to lower the nucleophilicity of the pyridine nitrogen to avoid an ionic reaction with the xanthate group starting by a nucleophilic attack on the thiocarbonyl group. Curtailing the nefarious effect of the pyridine nitrogen can be accomplished electronically, by protonation or by placing electro-withdrawing groups on the ring, or sterically by having a substituent on position 2 .

The examples collected in scheme 8 give an idea of the potential of this approach. The presence of the chlorine atom in most of the products is beneficial, both in counteracting the nucleophilicity of the pyridine nitrogen and in providing a handle for many subsequent transformations, especially as regards transition metal mediated coupling reactions. ${ }^{[33,34]}$ When two positions for cyclisation are available, a mixture of two regioisomers are generally observed, with one of the two often dominating. The conversion of adduct $\mathbf{5 2 f}$ thus furnishes azaindolines $\mathbf{5 3 f}$ and $\mathbf{5 3} \mathbf{f}^{\prime}$ in $18 \%$ and $68 \%$ yield respectively, in line with the earlier observations regarding the greater reactivity of the 2-position towards radical attack. ${ }^{[35]}$ Compounds $53 \mathbf{j}-\mathbf{n}$ are examples of diazaindolines derived from radical cyclisations onto a pyrimidine ring. ${ }^{[34]}$ Finally, several of the azaindolines in Scheme 8 were prepared directly, without isolation of the intermediate adducts $\mathbf{5 2}$. This is the case for azaindolines 53h-n.
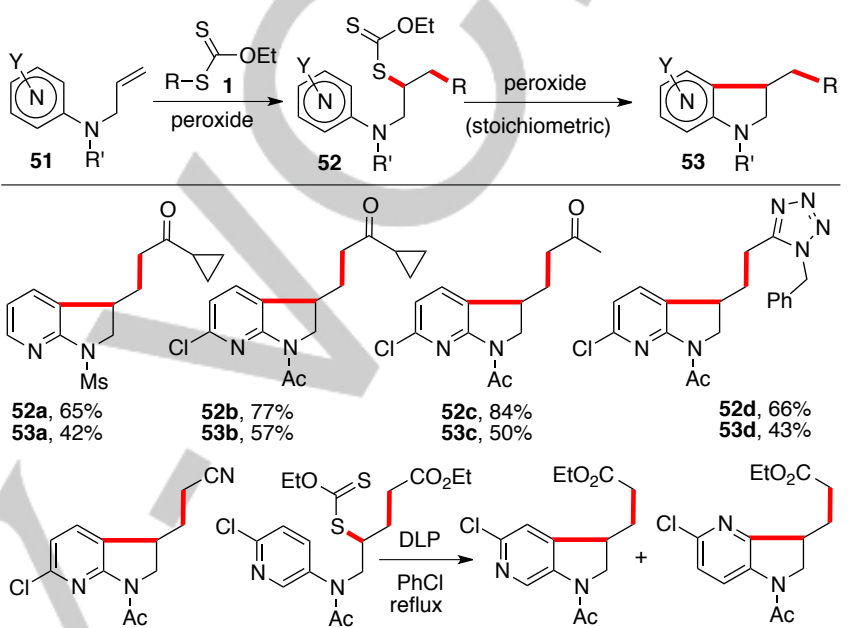

$$
\begin{array}{lccc}
\mathbf{5 2 e}, 97 \% & \mathbf{5 2 f}, 75 \% & \mathbf{5 3 f}, 18 \% & \mathbf{5 3 f}, 68 \% \\
\mathbf{5 3 e}, 72 \% & & &
\end{array}
$$

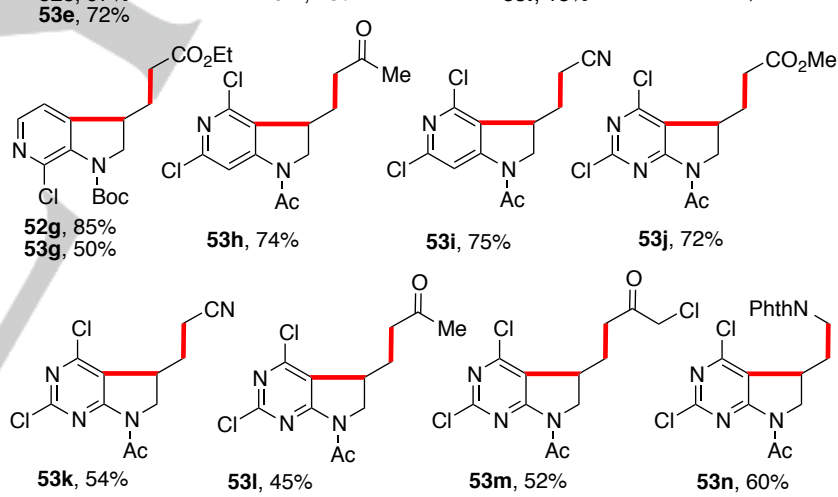

Scheme 8. Convergent Approach to Azaindolines and Diazaindolines.

In a similar manner to indolines, the large variety of functional groups that can be introduced authorizes numerous subsequent transformations to increase the diversity and complexity of the accessible azaindolines. A few examples are presented in Scheme 9. Protected ketoaldehyde 530 is thus readily converted into pyrazole 54 and chloroketone $53 p$ reacts with thionicotinamide to give thiazole $55 .{ }^{[33 b]}$ Trifluoromethyl chloroindoline 53q can be reduced into difluoroalkene $\mathbf{5 6}$ without harm to the fluorine present on the pyridine ring. ${ }^{[36]}$

The synthesis of azaindoline $53 \mathrm{r}$ underscores the compatibility of the radical process with the presence of iodine on the aromatic ring. ${ }^{[33 b]}$ This compound constitutes an interesting scaffold for generating libraries since it contains at least four points of diversification with orthogonal reactivities: the iodine, the chlorine, the extranuclear nitrogen, and the ketone. The Sonogashira coupling leading to alkyne $\mathbf{5 8}$ is an illustration of a chemoselective 
modification. It is also worth emphasizing the possibility of replacing the $t$-butyl ketone, which derives from the xanthate partner, with a plethora of other functional groups.

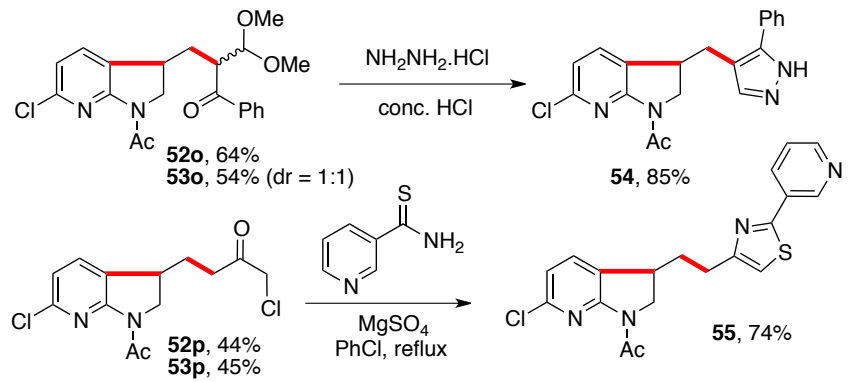

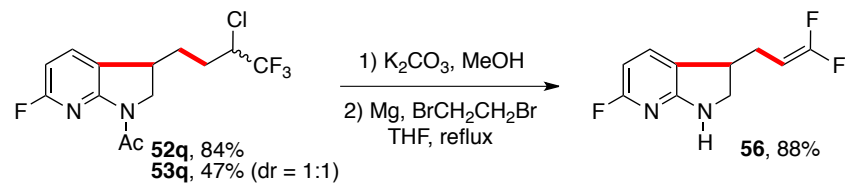

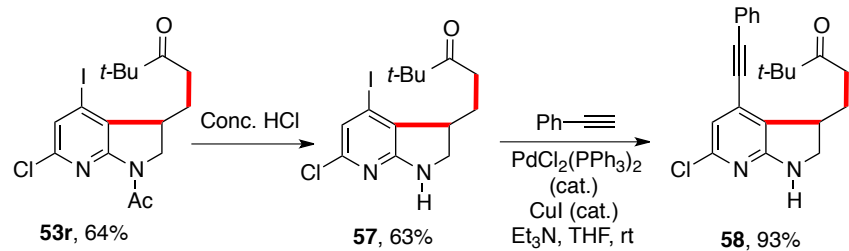

Scheme 9. Further Modifications of Azaindolines.

\section{Scheme 10. An Alliance with the Ugi-Smiles Reaction}

\subsection{Synthesis of 2-Substituted Indolines and Azaindolines}

The indolines described so far are substituted in the 3-position. Substituents in position 2 can be incorporated by starting with a more substituted allyl motif. A quite different and counterintuitive approach relies on vinylsulfonanilides such as 62 (Scheme 11). ${ }^{[39]}$ The addition cyclisation with xanthate 63 leads to sultam 64, a compound that undergoes cheletropic elimination of sulfur dioxide upon heating in refluxing o-dichlorobenzene. ${ }^{[40]}$ The highly reactive trans-azadiene 65 thus formed is in equilibrium with azetine 66, itself in equilibrium, via an electrocyclic ring opening, with cis-azadiene $\mathbf{6 7}$. This last intermediate is geometrically well disposed for an irreversible [1,5] sigmatropic rearrangement to give $N$-methyl aniline 68 . The sequence can be construed as a general method for the synthesis of o-substituted anilines. Advantage can be taken of the presence of the nitrile group in product 68 to reversibly isomerize the alkene and generate conjugated nitrile 69 that spontaneously closes into indoline $\mathbf{7 0 a}$. The same sequence can be applied using other xanthates bearing an electron-withdrawing group to facilitate the migration of the alkene and generate the internal Michael acceptor. Four additional examples 70b-e are given in Scheme 11, the last being an azaindoline. This strategy has certainly a much wider scope that still needs to be delineated.

El Kaïm and Grimaud reported a series of azaindoles possessing elaborate substituents on the indoline nitrogen. ${ }^{[3]}$ They associated the xanthate radical chemistry with the Ugi-Smiles reaction they invented. ${ }^{[38]}$ Thus, a mixture of allylamine, an aldehyde, an isonitrile, and a hydroxy pyridine or hydroxypyrimidine 59 evolves smoothly into compounds $\mathbf{6 0}$, which then undergo the same addition cyclisation with xanthates 1 to furnish the corresponding azaindolines 61 (Scheme 10). The intermediate radical adduct was not isolated, so the yields given for the six examples arrayed in Scheme 10 correspond to the direct conversion of amides 60 into azaindolines 61 .

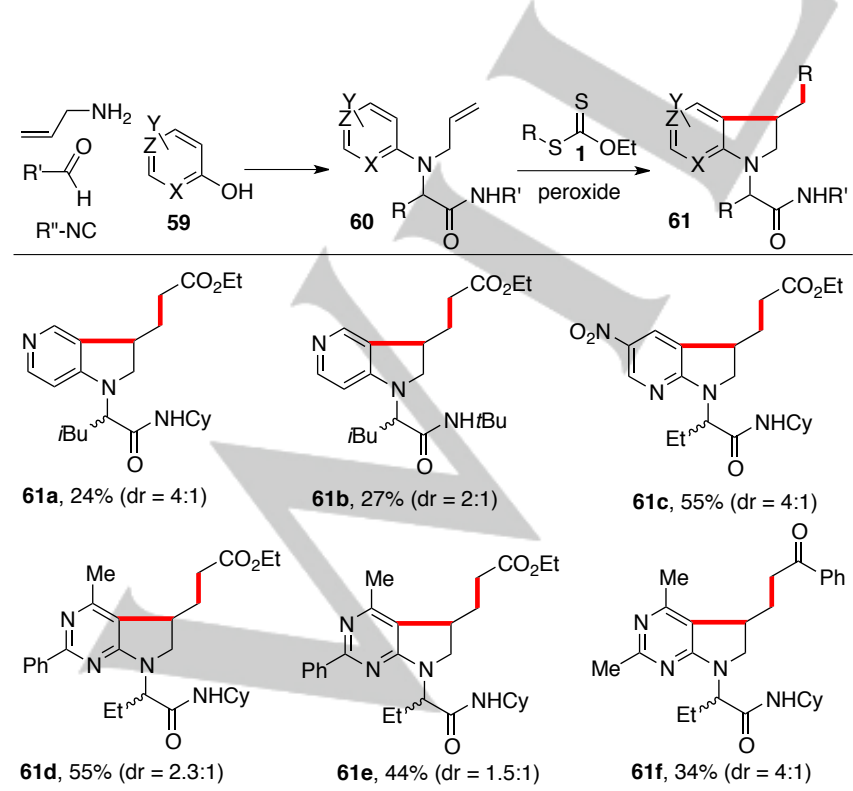

Scheme 11. An Unusual Route to 2-2ubstituted Indolines and Azaindolines.

\subsection{The Case of Fluoropyridines}

Pentafluoropyridine $\mathbf{7 1}$ is a relatively cheap commercial starting material for the synthesis of fluorinated pyridine derivatives. ${ }^{[11]}$ It reacts with allylamine chiefly at the 4-position to give after acetylation acetamide $\mathbf{7 2}$, a compound that reacts readily with xanthates 1 to give the usual adducts 73 (Scheme 12). ${ }^{[42]}$ Under somewhat forcing conditions, namely heating with di-t-butyl peroxide in refluxing chlorobenzene or amyl acetate, a rare homolytic ipso substitution of a fluorine takes place to give azaindoline 76. The sequence proceeding via intermediates $\mathbf{7 4}$ and $\mathbf{7 5}$ and final extrusion of a fluorine atom appears to be the most likely pathway, as all other alternatives are less 
reasonable. ${ }^{[42-44]}$ Homolytic rupture of a carbon-fluorine bond is very rare, but the substantial increase in entropy in the last fragmentation step and, especially, the restoration of aromaticity are strong driving forces.

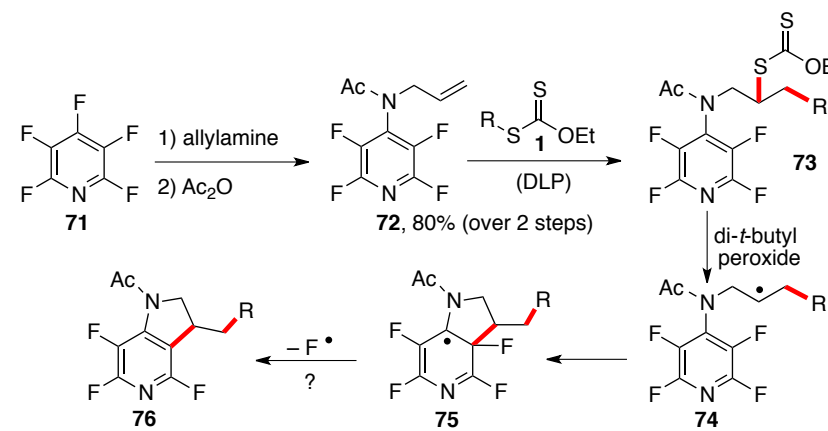

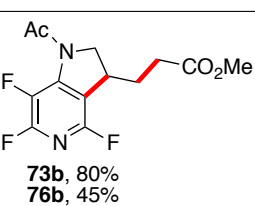

$$
\begin{aligned}
& \mathbf{7 3 b}, 80 \% \\
& \mathbf{7 6 b}, 45 \%
\end{aligned}
$$<smiles>CCOC(=O)C(C)CC1CN(C(=O)OCC)c2c(F)nc(F)c(F)c21</smiles>

73 e, $62 \%$

73d, $78 \%$

Ac<smiles>CCCOCC(=O)CCC1CN(C(=O)O)c2c(F)nc(F)c(F)c21</smiles>

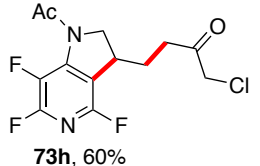

$$
\begin{aligned}
& \text { 73h, } 60 \% \\
& \mathbf{7 6 h}, 43 \%
\end{aligned}
$$<smiles>CC(F)(F)N1CC(CCC(=O)N2CCOC2=O)c2c(F)nc(F)c(F)c21</smiles>

$73 c, 95 \%$
$76 c, 40 \%$

Ac<smiles>O=C(O)N1CC(CCc2nnnn2Cc2ccccc2)c2c(F)nc(F)c(F)c21</smiles>
$73 f, 60 \%$
$76 f, 27 \%$ Ac

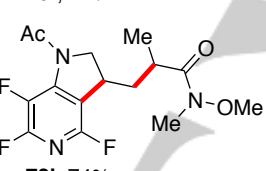
$73 \mathbf{i}, 74 \%(\mathrm{dr}=1: 1.5)$

$$
\text { (76j, 74\% (dr=1:1.5) }
$$

Scheme 12. Synthesis of Trifluoroazaindolines.

A variety of trifluoroazaindolines of general structure 76 can be obtained by this route, as indicated by compounds $76 \mathrm{a}-\mathrm{j}$ assembled in Scheme 12. ${ }^{[42]}$ The yields are moderate, but this is not unexpected in view of the difficult cyclisation step. Nevertheless, a short, convergent access to a hitherto unknown class of fluoroazaindolines is now available. Furthermore, a brief study indicated that tetrafluoroindolines can also be obtained, albeit in modest yields, as shown by the conversion of $\mathrm{N}$-allyl acetanilide $\mathbf{7 7}$ into indoline $\mathbf{7 9}$ via intermediate adduct $\mathbf{7 8}$ (Scheme 13). ${ }^{[42]}$

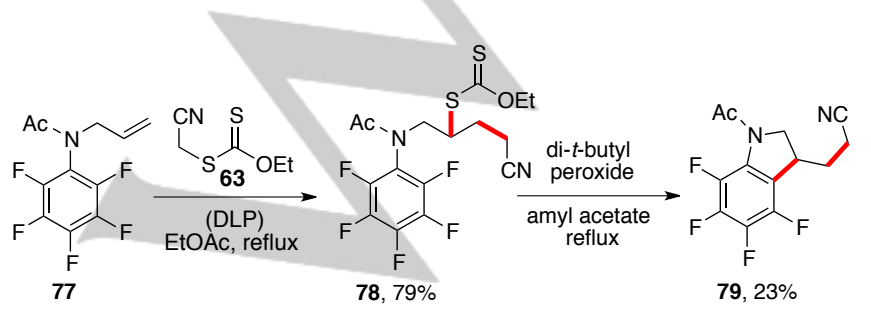

Scheme 13. An Example of a Tetrafluoroindoline.

Of the three fluorine atoms in azaindolines 76 , the ones on C-2 and C-6, adjacent to the nitrogen of the pyridine ring, are susceptible to nucleophilic substitution. However, substitution at $\mathrm{C}-6$ is hindered by the proximate 5 -membered ring and nucleophilic attack takes place preferentially on C-2. Thus, starting with compound $\mathbf{7 6 a}$, a variety of nitrogen, oxygen and sulfur nucleophiles could be regioselectively introduced to give substituted indolines $\mathbf{8 0 a - i}$, (Scheme 14). ${ }^{[43]}$ In the case of primary and secondary amines (80a-f), no addition of base is necessary. With imidazole and phenol $(\mathbf{8 0} \mathrm{g}$ and $\mathbf{8 0 h}$ ), the anion is generated with sodium hydride and the basic conditions of the reaction caused cleavage of acetyl group. This loss of the acetyl group is not observed with thiophenol adduct $(\mathbf{8 0 i})$.

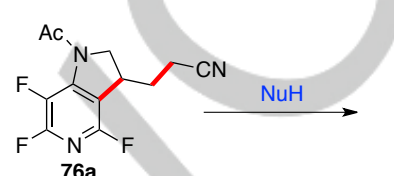<smiles>CN1CC(CCC#N)c2c(F)[nH+]c(N)c(F)c21</smiles>
80

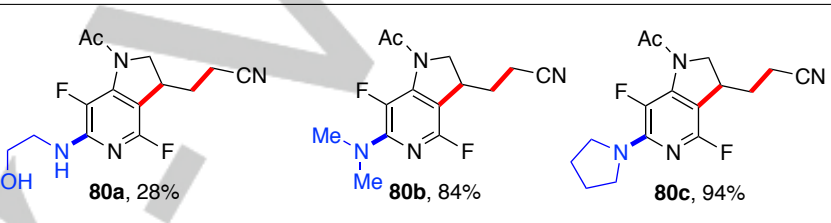
Ac

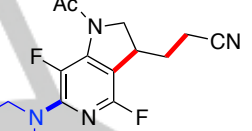<smiles>FCNCN1C=CCCC1</smiles>

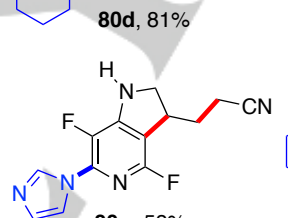<smiles>[14CH3]N1CC(CCC#N)c2c(F)c(N3CCOCC3)nc(F)c21</smiles><smiles>CN1CC(CCC#N)c2c(F)nc(NC3CC3)c(F)c21</smiles>
$80 f, 43 \%$
$80 \mathrm{~g}, 58 \%$<smiles>CCCC1CNc2c(F)nc(Oc3ccccc3)c(F)c21</smiles>

$80 \mathrm{~h}, 60 \%$<smiles>CN1CC(CCC#N)c2c(F)c(Sc3ccccc3)nc(F)c21</smiles>

$80 i, 61 \%$
Scheme 14. Further Modifications of Trifluoroazaindolines.

Azaindolines 80 result from the modular combination of four components: pentafluoropyridine $\mathbf{7 1}$, allylamine, xanthate $\mathbf{1}$, and the nucleophile. The last two are the most easily modified, allowing the construction of a diverse library of difluoroazaindolines $\mathbf{8 0}$ for eventual high throughput screening for biological activity. Even greater diversity can be achieved in principle by substituting the fluorine at C-6 with yet another nucleophile under more forcing conditions, making the overall process a five-component assembly. This has not yet been attempted but has a high probability of success.

By interchanging the substitution with the nucleophile and the reaction with allylamine, a completely different family of difluoroazaindolines can be prepared. This variant is outlined at the top of Scheme 15. ${ }^{[44]}$ The reaction of the nucleophile with pentafluoropyridine now occurs at position 4 , and the allylamine is introduced at position 2 to give precursor $\mathbf{8 2}$ after acetylation. The radical addition of a variety of xanthates 1 to give adducts 83 proceeds normally and in generally high yield but, surprisingly, the ring closure results in the formation of significant amounts of the difuoroazaindoles 85, in addition to the expected difluoroazaindolines $\mathbf{8 4}$. The combined yield is quite respectable in most cases. 

scope. ${ }^{[44]}$ The amount of difluoroazaindoles is variable and depends on the nature of the nucleophile introduced at C-4 of the negligible $(<5 \%)$ in the cyclization of bromo- and iodo-aniline substituted xanthates $\mathbf{8 3 f}$ and $\mathbf{8 3 g}$.
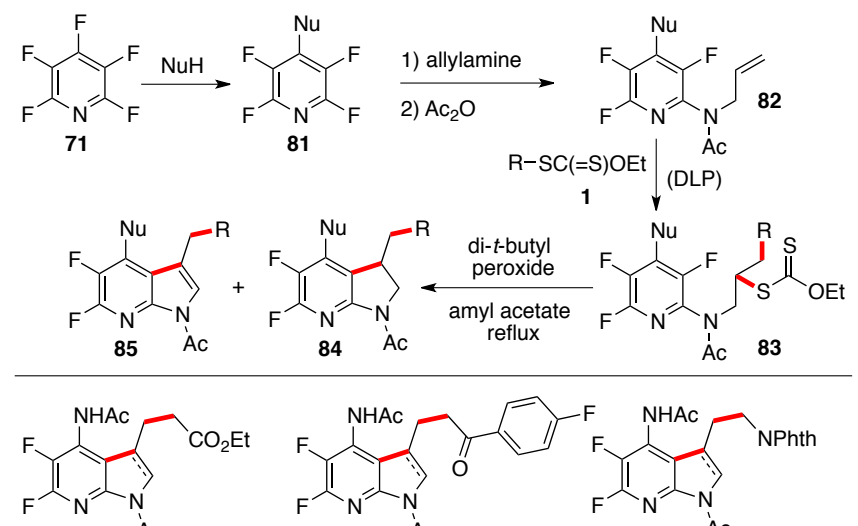

83a, $63 \%$ Ác

$83 a, 63 \%$
$84 a+85 a, 50 \%+20 \%$<smiles></smiles><smiles>CNc1c(F)c(F)nc2c1c(CCNc1ccccc1)cn2C</smiles>
$\mathbf{8 3 b}, 85 \%$
$\mathbf{8 4 b}+\mathbf{8 5 b}, 50 \%+12 \%$ 83c, $73 \%$<smiles>CCOC(=O)CCc1cn(C)c2nc(F)c(F)c(N(C)C3CC3)c12</smiles><smiles>CCOC(=O)CCc1cn(C)c2nc(F)c(F)c(N(C)C)c12</smiles>
83d, $84 \%$ $\mathbf{8} \mathbf{8} d \mathbf{d}+\mathbf{8 5}$ d, $43 \%+18 \%$<smiles>Cn1cc(CCC(=O)C2CC2)c2c(Nc3ccc(I)cc3)c(F)c(F)nc21</smiles>

$84 \%$ $84 \mathrm{e}+85 \mathrm{e}, 46 \%+18 \%$ $\mathrm{Cl}$<smiles>Cc1ccc(Oc2c(F)c(F)nc3c2c(CCC#N)cn3C)cc1</smiles>

$\mathbf{8 4 g}+\mathbf{8 5 g}, 53 \%+<5 \%$ $83 \mathrm{~h}, 98 \%$
$84 \mathrm{~h}+\mathbf{8 5 h}, 37 \%+24 \%$ $\mathbf{8 3 f}, 72 \%$
$\mathbf{8 4 f}+\mathbf{8 5 f}, 39 \%+<5 \%$

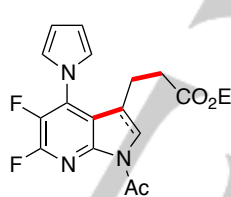
$83 \mathbf{i}, 53 \% \quad A c$<smiles>Cn1cc(CCC(=O)C(C)(C)C)c2c(-n3cncn3)c(F)c(F)nc21</smiles>
$83 \mathbf{k}, 81 \%$ Ac $84 k+85 k, 61 \%+18 \%$
The variety of the examples in Scheme 15 provides an idea of the pyridine ring. For reasons not yet clear, indole formation is almost 83b, $85 \%$ Ac<smiles>C1=CC2CCCC2=C1</smiles><smiles></smiles>
$31,75 \%$ $84 I+85 I, 42 \%+18 \%$ by DMSO $^{[45]}$ affords fluoroazaindole 87 in $23 \%$ yield overall. More traditional, milder oxidizing agents such as manganese dioxide fail to perform the same transformation, underscoring the deactivating effect of the fluorine atoms. It is interesting to note that of the five fluorine atoms present in pentafluoropyridine $\mathbf{7 1}$, only one remains in the final indole $\mathbf{8 7}$.

The same oxidizing system can be applied to difluoroazaindoline 88, belonging to the first series (see Schemes 12 \& 14) and prepared from trifluoroazaindoline 73 a followed by cleavage of the acetyl group. ${ }^{[43]}$ Notice that in this case the fluorine atom on C-6 is not replaced by a methoxy group from the methanol solvent, no doubt because of increased steric hindrance at this position in comparison to $\mathrm{C}-2$ in $\mathbf{8 4 m}+\mathbf{8 5 m}$. The modest yield in the aromatization into azaindole $\mathbf{8 9}$ reflects once again the unfavorable influence of the fluorine atoms.
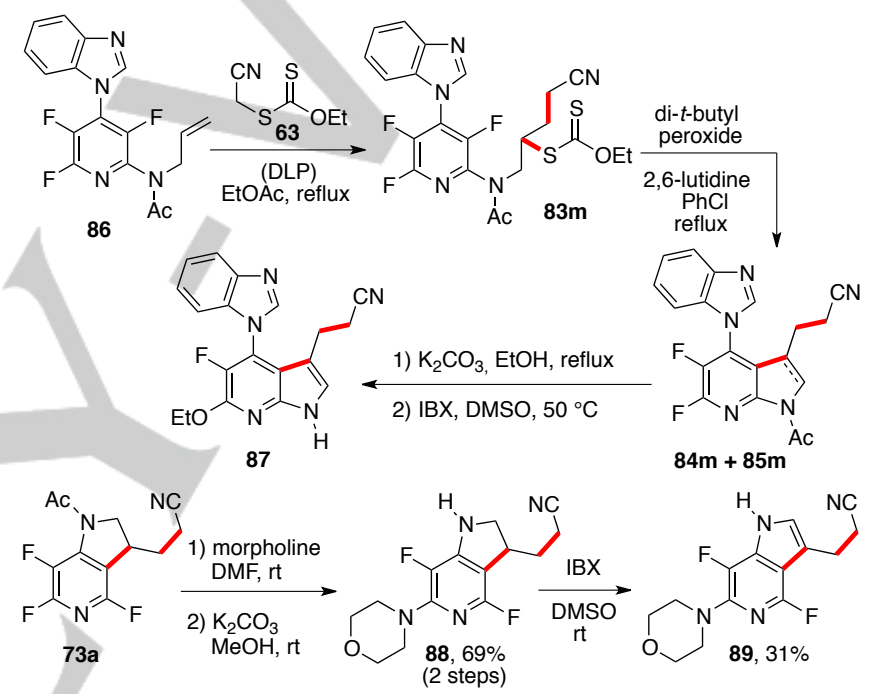

Scheme 16. Oxidation of Azaindolines into Azaindoles.

\section{Indoles from Indolines}

\subsection{Oxidation of Indolines}

Scheme 15. Azaindolines and Azaindoles.

In contrast to the fluoroazaindolines above, which require somewhat drastic conditions, indolines can generally be dehydrogenated using mild oxidants. ${ }^{[46]}$ Thus, all the indolines described so far can in principle be converted into the corresponding indoles. Indeed, the alliance of the radical additioncyclisation of xanthates with the oxidation step represents a powerful synthesis of indoles. One example is depicted in Scheme 17, where addition of xanthate 91 to allylaniline 90 furnishes adduct 92. ${ }^{[2]}$ Further exposure of the latter to stoichiometric amounts of peroxide induces ring closure into indoline 93, and oxidation with manganese dioxide completes the synthesis of indole 94 bearing two amino groups protected as phthalimides. Access to such an indole by more traditional approaches would be considerably more laborious. 


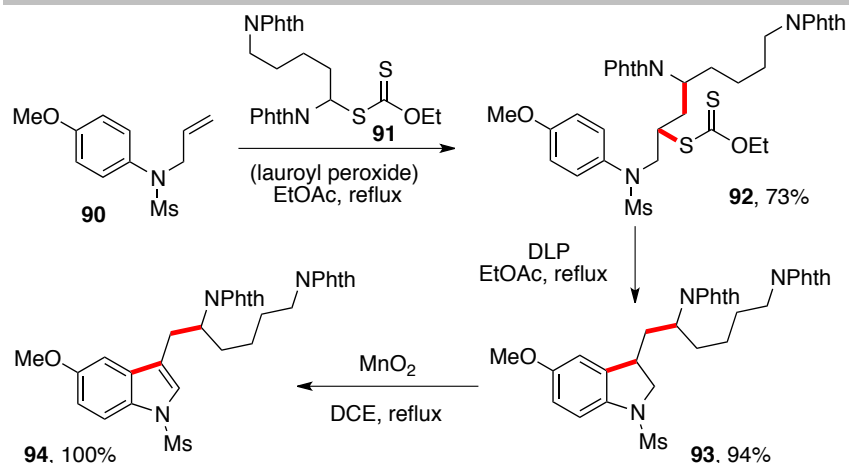

Scheme 17. Synthesis of an Indole by Oxidation of the Indoline.

\subsection{Indoles by Isomerization of 3-Vinylindolines}

An alternative route to indoles, applicable in certain situations, was uncovered when an attempt was made to eliminate the chlorine from chlorodifluoromethyl indoline 97 (Scheme 18). ${ }^{[47]}$ This compound is efficiently prepared in one step from xanthate 96 and allyl aniline 95 . Indeed, heating in neat DBU at $50{ }^{\circ} \mathrm{C}$ or below furnishes the desired difluorovinyl indoline 98; however, raising the temperature to $90^{\circ} \mathrm{C}$ in order to accelerate the process results in the formation of indole $\mathbf{9 9}$ and loss of the mesyl group. Under these harsher basic conditions, the initial alkene in compound $\mathbf{9 8}$ migrates into the five-membered ring followed by hydrolysis of the mesyl group by adventitious water in the nonanhydrous medium. In contrast to $\mathrm{N}$-sulfonyl indolines, $\mathrm{N}$-sulfonyl indoles are readily hydrolysed because of the greater acidity, and hence leaving group ability, of indoles as compared to indolines.
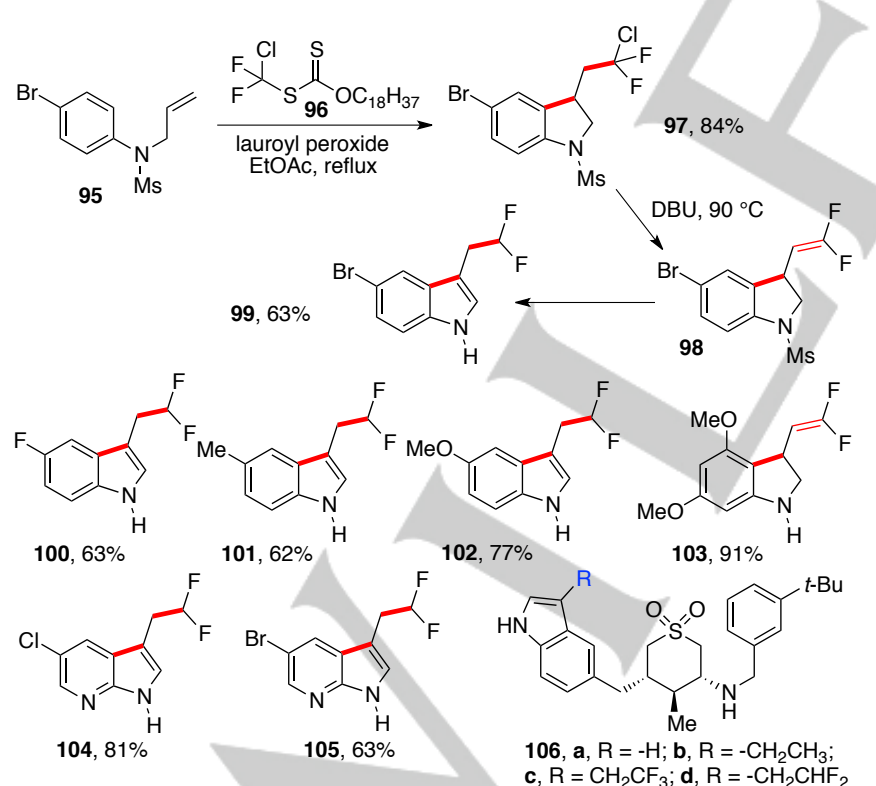

Scheme 18. Synthesis of 3-Difluoroethylindoles.

Five other examples are displayed in Scheme 18, including two difluoroethyl azaindoles 104 and 105. In the case of the dimethoxy derivative, no indole was formed; only elimination of the chloride to give difluorovinyl indoline $\mathbf{1 0 3}$ was observed. The introduction of a difluoroethyl group is of some importance in medicinal chemistry. For example, the activity of BACE-1 inhibitors 106a-d is greatest for difluoroethyl derivative $106 \mathbf{d} .{ }^{[48]}$ The trifluoroethyl, the non-fluorinated ethyl, and the unsubstituted analogues 106c, 106b and 106a are respectively two, four, and fifty times less active.

\subsection{Indoles by Elimination of Methanesulfinic acid}

In the course of examining ring closures employing Friedel-Crafts conditions discussed above (Scheme 7), an unexpected conversion of indolines to indoles was observed involving elimination of the mesyl group on the indoline nitrogen. ${ }^{[49]}$ This occurrs with electron-rich derivatives such as 107 (Scheme 19). In cold concentrated sulfuric acid, the mesyl group is protonated and then expelled to give indole 111 via intermediates 108-110. This reaction is not general but nevertheless useful is certain situations, as shown by examples 111a-d displayed in the lower part of Scheme 19. Interestingly, under the conditions specified, no serious competition from the Friedel-Crafts reaction is observed in the case of ketones 111a-c.

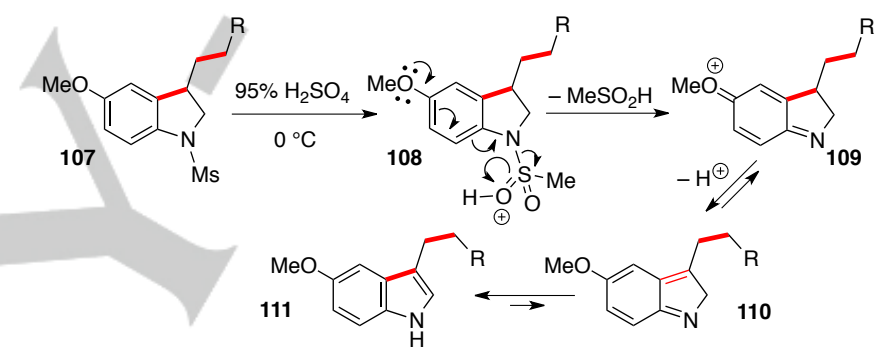<smiles>COc1ccc2[nH]cc(CC(NC(=O)OCc3ccccc3)C(=O)OCc3ccccc3)c2c1</smiles>

Scheme 19. Indolines by Acid Induced Elimination of Methanesulfonic Acid

One practical application of this method is the synthesis of melatonin, a hormone implicated in synchronizing the circadian rhythm and widely used to help with jet-lag related sleeping troubles. Melatonin 111e possesses a 5-methoxy-indole motif and is thus ideally suited for this approach (Scheme 20). ${ }^{[49]}$

Addition of xanthate $\mathbf{1 1 2}$ to allyl aniline $\mathbf{9 0}$ gives adduct $\mathbf{1 1 3}$ and subsequent cyclization furnishes indoline 114. Hydrolysis of the ester with concentrated hydrochloric acid, followed by Curtius rearrangement mediated by diphenylphosphoryl azide $115^{[50]}$ and treatment of the intermediate isocyanate without isolation with acetic anhydride and acetic acid affords a mixture of acetamide 116 and acetimide (not shown). The latter is converted into the former by a brief contact with potassium carbonate in methanol. Finally, exposure to cold sulfuric acid provides the desired melatonin 111e. A slightly shorter variation consists in first exposing indoline $\mathbf{1 1 4}$ to cold sulfuric acid, which causes elimination of methanesulfinic acid and cleavage of the ethyl ester. A similar Curtius rearrangement and acetylation yields melatonin $111 \mathrm{e}$ with comparable efficiency. ${ }^{[49]}$ 


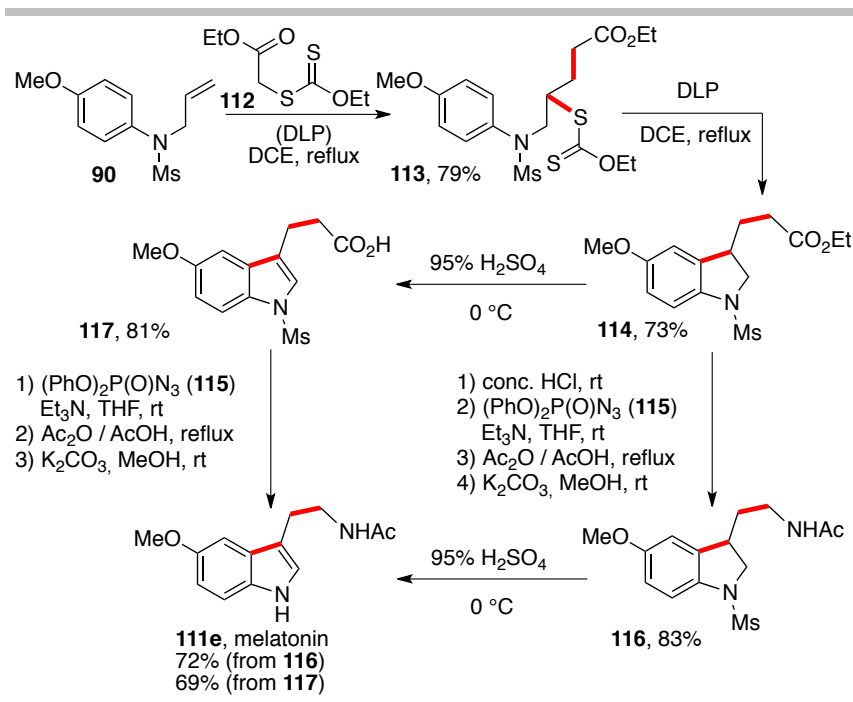

Scheme 20. A First Synthesis of Melatonin.

A more concise synthesis was later devised hinging on the use of acetimide xanthate 118. ${ }^{[50]}$ Radical addition to the same allyl aniline $\mathbf{9 0}$ gives the corresponding adduct 119 and ring-closure followed by in situ cleavage of the acetimide group with triethylamine and methanol leads to the same intermediate 116. Treatment with cold sulfuric acid finally affords melatonin 111e. This sequence is more atom-economical and more safely scalable as it does not involve a Curtius rearrangement and the intermediacy of hazardous azides.

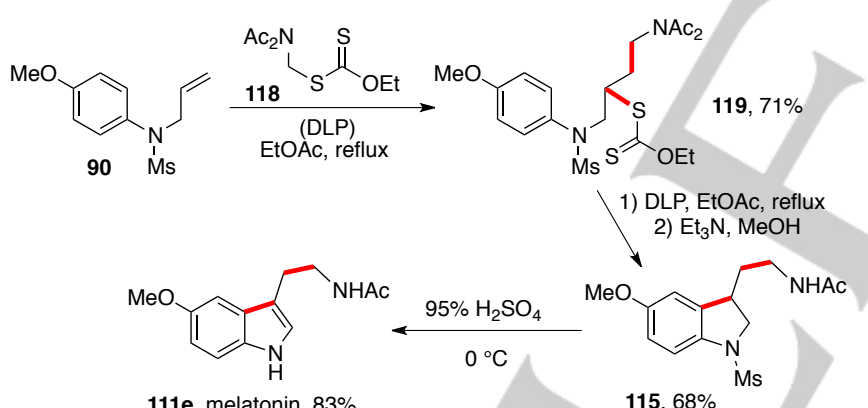

Scheme 21. A Second Synthesis of Melatonin

\section{Modifications of Existing Indoles}

\subsection{Formation of Seven-Membered Rings}

The third powerful way to access indoles (and indirectly indolines by reduction) is to use xanthate chemistry to modify existing indole structures. This may be accomplished through radical cyclisation or by intermolecular radical addition to the indole nucleus. Both of these two approaches will now be discussed.

The pyrrole portion of the indole ring system is fairly reactive towards radical addition. ${ }^{[6]}$ Indeed, this can prove to be a complicating factor in certain situations. One such instance is outlined in Scheme 22. ${ }^{[52]}$ In a model study aiming at the synthesis of eburna alkaloids, it was found that the addition of xanthate $\mathbf{1 2 1}$ on alkene $120(R=$ Boc) gives the anticipated adduct 122 unexpectedly accompanied by an equal amount of azepine 123 . The bulk of the Boc group is not sufficient to prevent this unwanted cyclization and the more ponderous $t$-butyldimethylsilyl (TBS) group had to be used. The corresponding adduct 124 is thus obtained free from azepine side product 125 and converted into the desired tetracyclic derivative 128 by reduction of the xanthate (126), deprotection of the indole nitrogen (127), and trifluoroacetic acid (TFA) induced cleavage of the acetal, iminium ion formation and intramolecular Pictet-Spengler reaction.

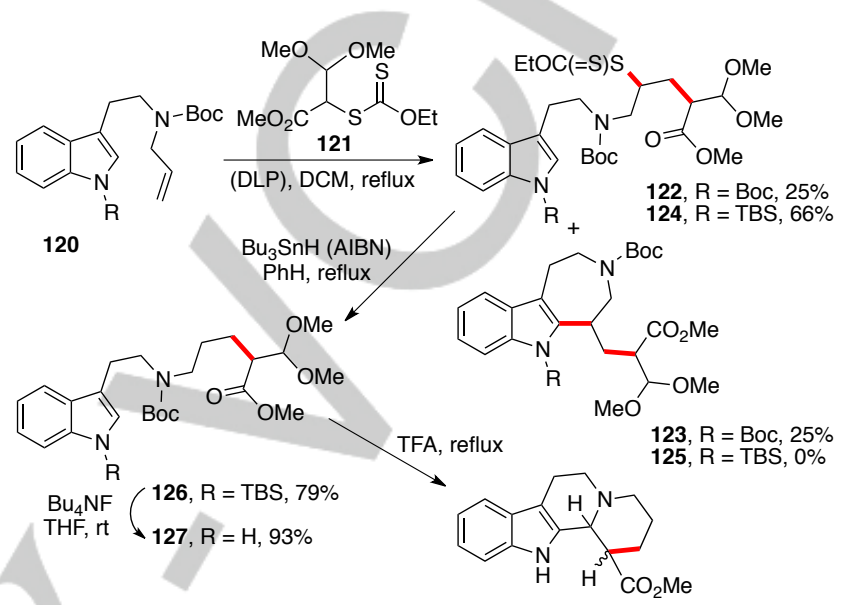

128, $71 \%$; cis:trans $=4: 1$

Scheme 22. A Route to the Eburna Alkaloid Skeleton.

The formation of the fused seven-membered ring can be made deliberate in various manners. Three examples staring from xanthates 129a-c derived from $\mathrm{N}$-methyl tryptamine and the methyl ester of $\mathrm{N}$-methyl tryptophan are pictured in Scheme 23. ${ }^{[53]}$ Treatment with stoichiometric amounts of lauroyl peroxide delivers as expected indoloazepinones 130a-c in synthetically useful yields.

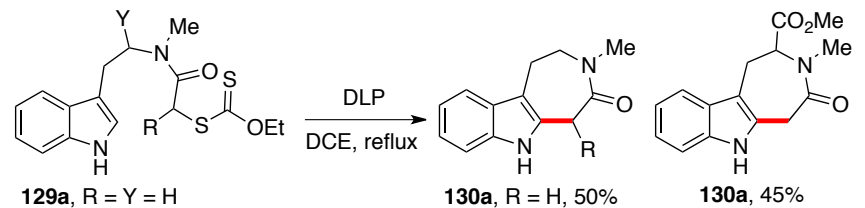

$129 a, R=Y=H$
$129 b, R=M e ; Y$ 129c, $\mathrm{R}=\mathrm{H} ; \mathrm{Y}=\mathrm{CO}_{2} \mathrm{Me}$

130a, $\mathrm{R}=\mathrm{H}, 50 \%$ 130b, $\mathrm{R}=\mathrm{Me}, 54 \%$ $130 a, 45 \%$

Scheme 23. Formation of Indoloazepinones.

In an extension of this approach, Gámez-Montaño and coworkers exploited the Ugi azide multicomponent reaction to prepare a series of xanthates $\mathbf{1 3 1}$ from tryptamine as the amine component, as shown in Scheme 24. ${ }^{[54]}$ These were then cyclized in the usual manner to furnish a small library of indoloazepinones 132a-h bearing a substituted tetrazole appendage on the sidechain. 


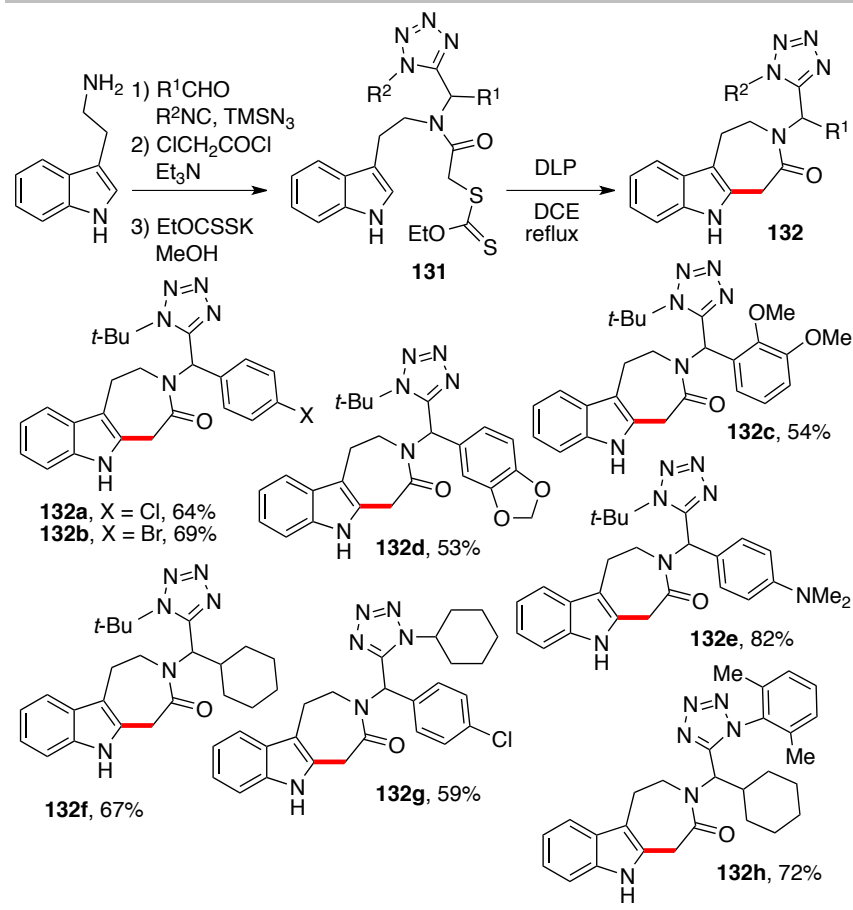

Scheme 24. Synthesis of Indoloazepinones with a Tetrazole Appendage.

Position 2 of the indole is the most reactive and is the site of attack in the above examples. If this position is substituted, then cyclization occurs at C-4 on the benzene portion of the indole. This variant is illustrated by the transformations in Scheme 25. ${ }^{[53]}$ Thus, xanthate 133 adds efficiently to allyl acetate to give adduct 134a. Further treatment with the peroxide induces ring-closure to furnish tricyclic indole 135a. Analogues $135 \mathrm{~b}$-e were prepared by simply varying the alkene partner. The yields of both the tricyclic products and the intermediate adducts are displayed. Once again, note the higher yield of the intermolecular addition step as compared to the cyclization. This reflects the general difficulty in constructing seven-membered rings, especially by direct radical addition onto an aromatic nucleus. If no substituent is desired on $\mathrm{C}-2$, this position could be temporary blocked for example by a $t$ butyl carboxylate, which can later be removed through acid hydrolysis and decarboxylation (see conversion of $t$-butyl indolecarboxylate $137 \mathrm{n}$ into 3-unsubstituted indole 138 in Scheme 27 below).

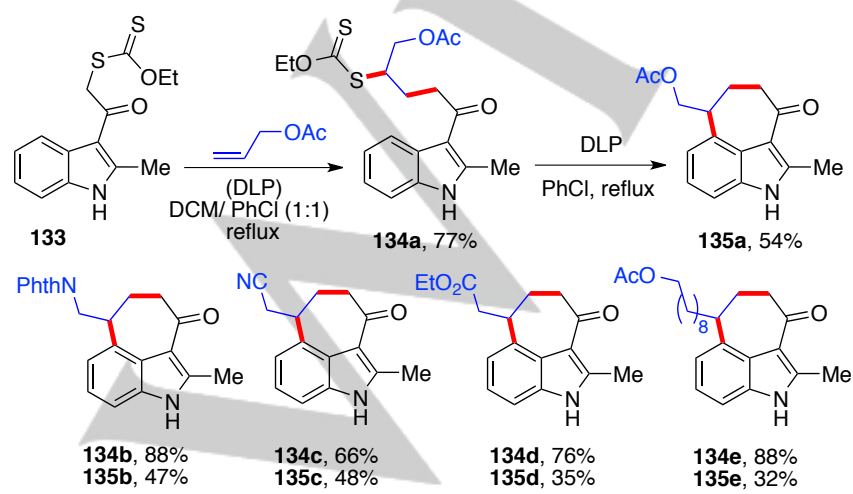

Scheme 25. Seven-Membered Rings by Closure on C-4.

\subsection{Formation of Six-Membered Rings}

Six-membered rings can also be fused to the indole nucleus. One particularly useful possibility is to attach the xanthate group to the indole nitrogen, as in structure 136 (Scheme 26). ${ }^{[55]}$ The addition to the alkene is now followed by ring closure on C-2 of the indole to give tricyclic compound 137 . This indeed proved feasible and numerous such tricyclic derivatives could be prepared. It was found, however, that the (reversible) cyclization step is inefficient in the absence of a substituent on C-3 of the indole. Such a substituent is needed to stabilize the adduct radical and drive the equilibrium towards the cyclized form. The oxidation step, necessary for restoring the aromaticity, is unfortunately not complete in many of the examples and the indoline side-product (not shown) has to be dehydrogenated with excess manganese dioxide.
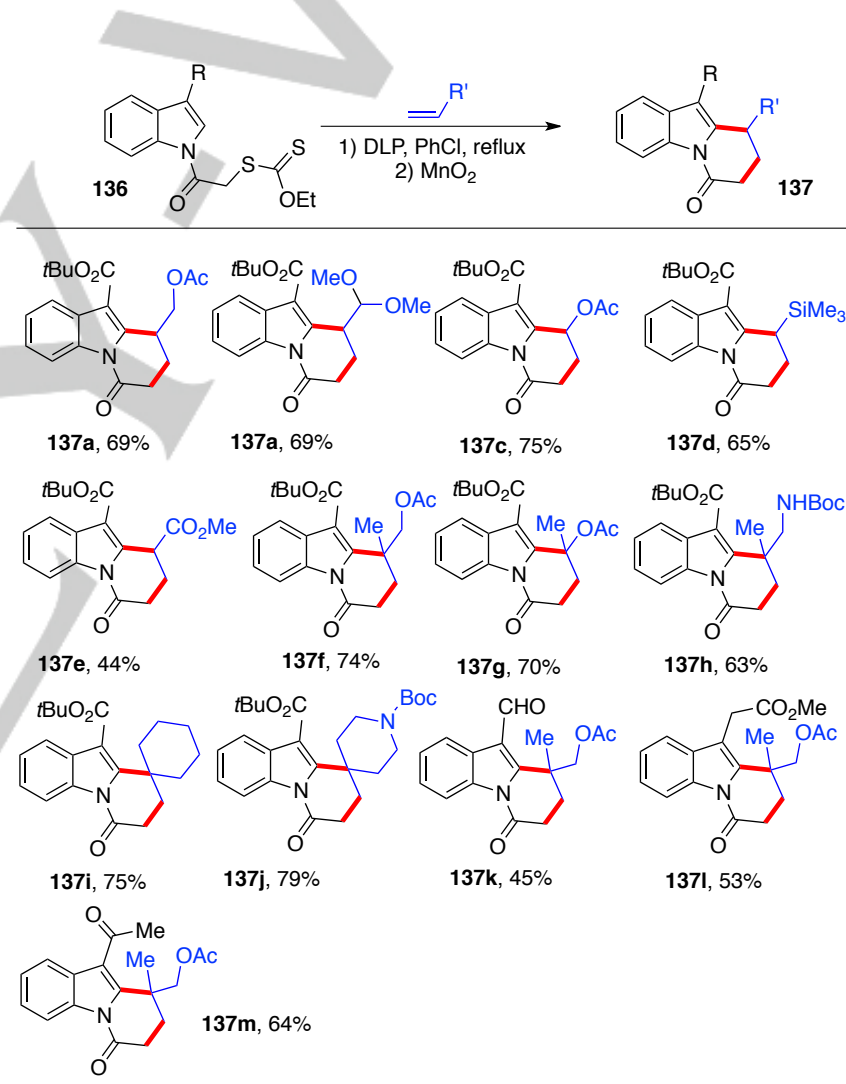

137d, $65 \%$

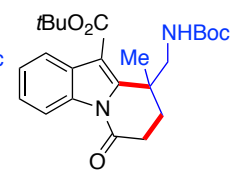

$137 \mathrm{~h}, 63 \%$

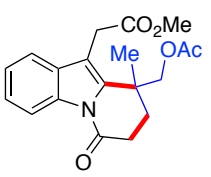

$1371,53 \%$

Scheme 26. Synthesis of Indoles with Fused 6-Membered Rings.

Despite these minor limitations, this convergent route provides an expedient access to interesting tricyclic indoles with many different functionalities, as exemplified by compounds $137 \mathrm{a}-\mathrm{m}$ in Scheme 26. ${ }^{[5]}$ The remarkable ability to generate quaternary centers, as in derivatives $137 \mathrm{f}-\mathrm{m}$, could be further exploited in a short, formal synthesis of ( \pm )-mersicarpine 139, an alkaloid of the Kopsia family (Scheme 27). ${ }^{[55]}$ The sequence commences with tricyclic indole derivative $137 \mathrm{n}$, obtained in a similar manner to its congeners in scheme 26. Treatment with trifluoracetic acid removes both the $t$-butoxycarbonyl group on $\mathrm{C}-3$ of the indole ring and the Boc group on the side chain amine. The latter must be 
reinstalled to give compound $\mathbf{1 3 8}$, a key intermediate in a prior total synthesis by Kerr and co-workers who successfully converted it into ( \pm )-mersicarpine 139 in only three steps. ${ }^{[56]}$ Many other alkaloids of the same family could benefit from the convergence and flexibility of this approach.

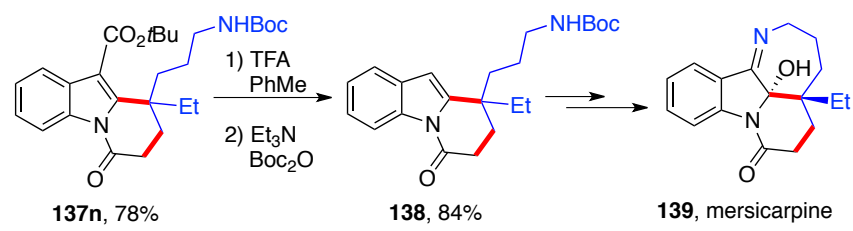

Scheme 27. Formal Synthesis of ( \pm )-Mersicarpine.

\subsection{Intermolecular Additions to Indoles}

The intermolecular radical addition to indoles is a simple, straightforward manner to obtain a broad variety of substituted indoles. Xanthates have proved particularly powerful in this respect. The generic process is depicted at the top of Scheme 28 and many examples 141a-aa are collected below. The first instances (141h and 141i) were reported by Miranda and coworkers. ${ }^{[57]}$ Later, many more examples were added by Miranda, ${ }^{[58]}$ ourselves ${ }^{[20,22,59-61]}$ and others. ${ }^{[62]}$

Halides on the aromatic ring, especially bromine and iodine (141f and $141 \mathrm{~g}$ ), are not affected, thus allowing numerous postmodifications relying on powerful transition metal catalyzed coupling reactions. The tolerance for the presence of an aldehyde group is also remarkable (141a-g, 141i, and 141q). The direct introduction of $\alpha$-trifluoromethyl acetamide $(141 q-v)$ is of medicinal interest since such motifs are considered to be peptide bond surrogates. ${ }^{[63]}$ Examples $141 \mathrm{y}$ and $141 \mathrm{z}$ illustrate the attachment of an azetidine and a complex $\beta$-lactam. The latter is particularly impressive and would be difficult to obtain otherwise. In recent times, medicinal chemists have been attracted by small ring substituents which appear to have beneficial effects on biological activity and metabolic stability. ${ }^{[64]}$ Last but not least, indole 141 aa derives from addition of xanthate 30 , itself prepared by addition of malonyl xanthate 28 to imidazolinone 29 (see Scheme 4). ${ }^{[22]}$ The ability to mediate multiple additions is one of the hallmarks of the radical chemistry of xanthates; it provides access to heavily functionalized structures that are beyond the reach of other methods, radical or otherwise.

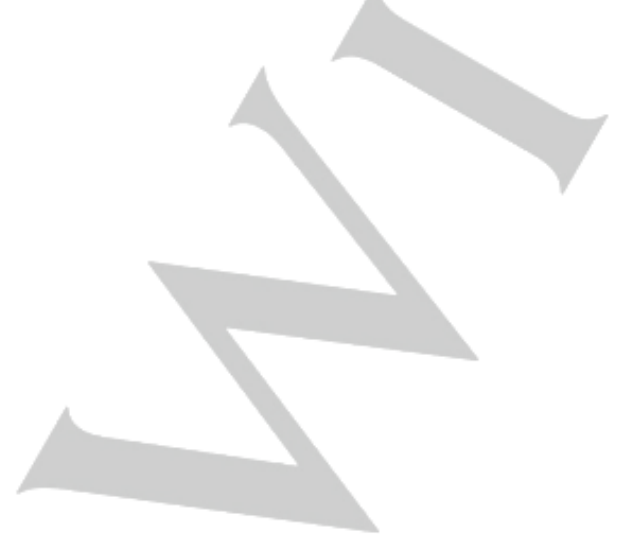

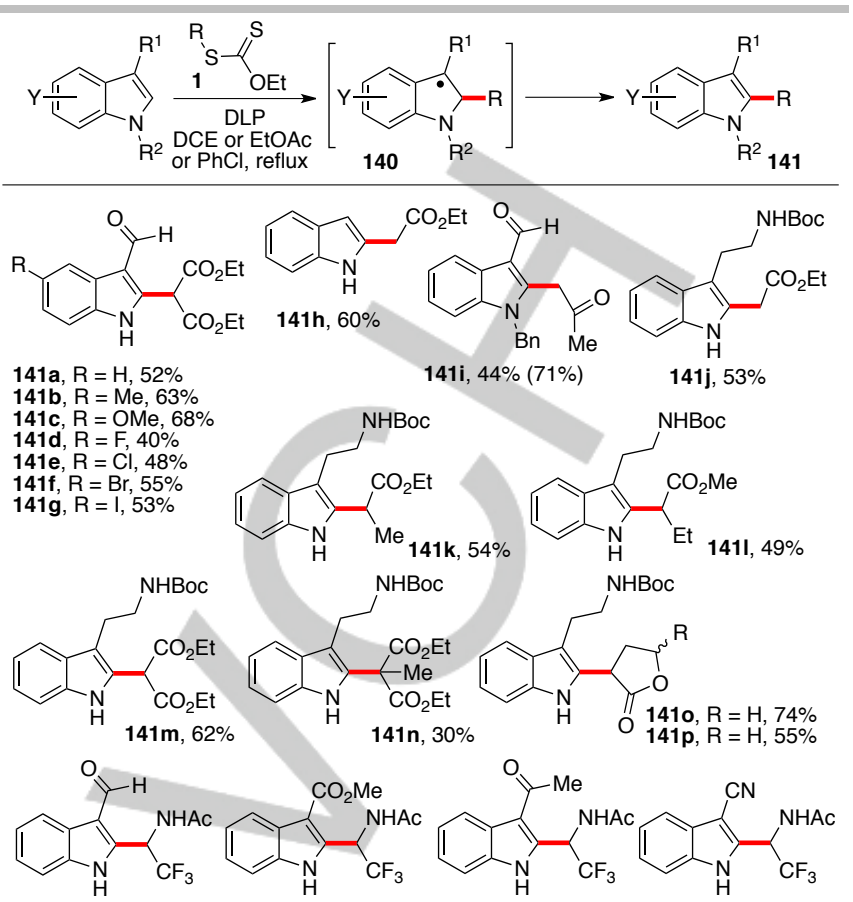

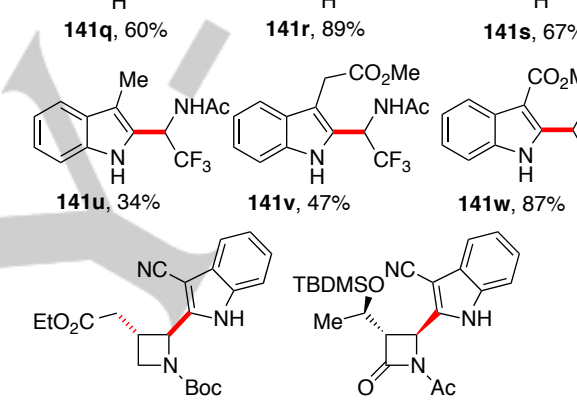

$141 y, 54 \%(67 \%)$

Scheme 28. Examples of Intermolecular Additions to Indoles.

Tertiary radicals, such as a $t$-butyl (141ab, Scheme 29), are sufficiently stabilized and can be incorporated directly, in contrast to less stable primary radicals. ${ }^{[65]}$ Such motifs have to be introduced in a latent form (see the synthesis of compound $\mathbf{3 4}$ in Scheme 5). To attach a methyl or an ethyl group to the indole, a simple method is to introduce first an acetic or propionic acid moiety, as shown for compounds 141 ac and 141 ae, by reacting ethyl 3-indolecarboxylate with the corresponding xanthate. ${ }^{64]}$ Brief heating in a microwave oven induces decarboxylation to furnish the methyl and ethyl substituted indoles 141ad and 141af respectively.

Addition on C-2 of the indole is favored over addition on C-3. This can be seen in example $141 \mathrm{~h}$ in Scheme 28 which involves addition to indole itself. ${ }^{[57]}$ If $\mathrm{C}-2$ is substituted, then addition has to take place on $\mathrm{C}-3$. This is indeed what happens in the case of examples $142 a$ and $142 b$, even if the yield is rather modest. ${ }^{[59,64]}$ A more effective addition is observed with the acetic and propionic acid motifs (142c and 142e). ${ }^{[6]}$ Decarboxylation to give the 3methyl and the 3-ethyl substituted indoles $142 \mathrm{~d}$ and $142 \mathrm{f}$ can also be accomplished, albeit under harsher conditions. $N$ Methylpyrrolidone (NMP) had to be used instead of $\mathrm{N}$-dimethyl acetamide (DMA) to avoid decomposition of the solvent because of the higher temperatures and longer heating times. ${ }^{[6]}$ 


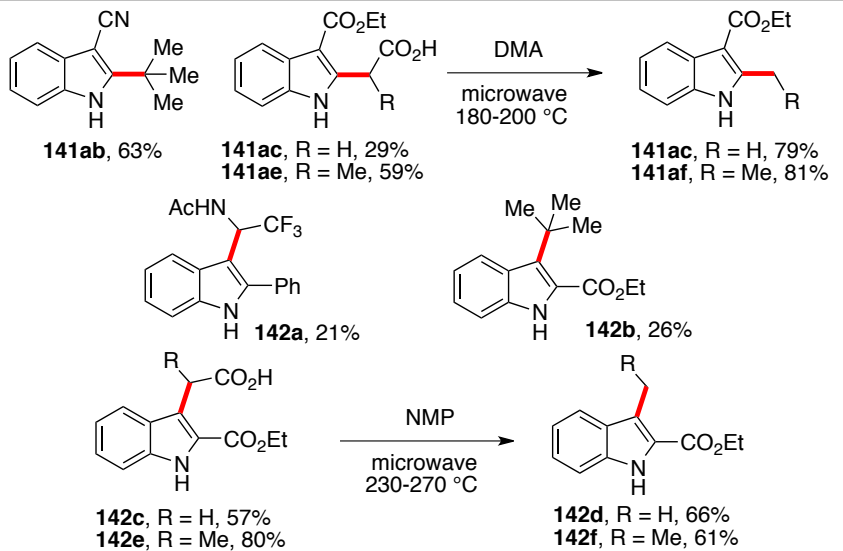

Scheme 29. Further Examples of Intermolecular Additions to Indoles.

The ability to decorate directly the indole nucleus at both C-2 and C-3 opens many opportunities for the synthesis of indole alkaloids. Two examples are provided in Schemes 30 and 31. The first is the synthesis of caulerpin 143a and various simple analogues 143b-g by Martínez and co-workers. ${ }^{[62]}$ Caulerpin 143a is a bisindole alkaloid isolated from marine algae, Caulerpa racemosa and Caulerpa serrulata, and reported to exhibit various biological activities, especially against tuberculosis. The syntheses start from adducts $141 \mathrm{a}-\mathrm{g}$, prepared by addition of malonyl xanthate to indole-3-carboxaldehyde (see Scheme 28). Treatment with sodium methoxide in methanol converts the diethyl malonate group into a simple methyl ester through a retro-Claisen condensation and transesterification. This is followed by heating with a combination of diethylamine and piperidine in refluxing xylene to give caulerpin and its analogues 143a-g by a double condensation process. The yields shown are for the last condensation step. They are modest but the synthesis is quite straightforward.

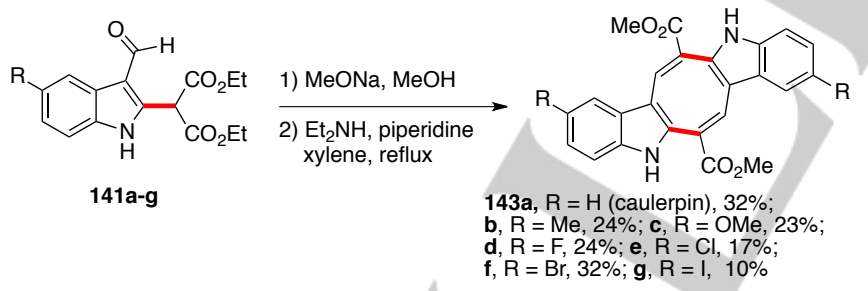

Scheme 30. Synthesis of Caulerpin and Analogues Thereof.

The second example concerns model studies towards the total synthesis of tronocarpine 148, a pentacyclic alkaloid isolated from Tabernaemontana corymbosa (Scheme 31).[67] Adduct 144, obtained in good yield by addition of malonyl xanthate to Bocprotected tryptamine, is the starting point. Michael addition to unsaturated aldehyde $\mathbf{1 4 5}$ is followed by treatment with acid, which causes cyclization of the aldehyde on the indole nitrogen and removal of the Boc group from the side-chain amine. Under basic conditions, the liberated amino group closes onto one of the malonyl esters to give finally amide 146. Catalytic hydrogenation of the alkene and Claisen condensation completes the assembly of the desired pentacyclic skeleton 147 found in tronocarpine 148.

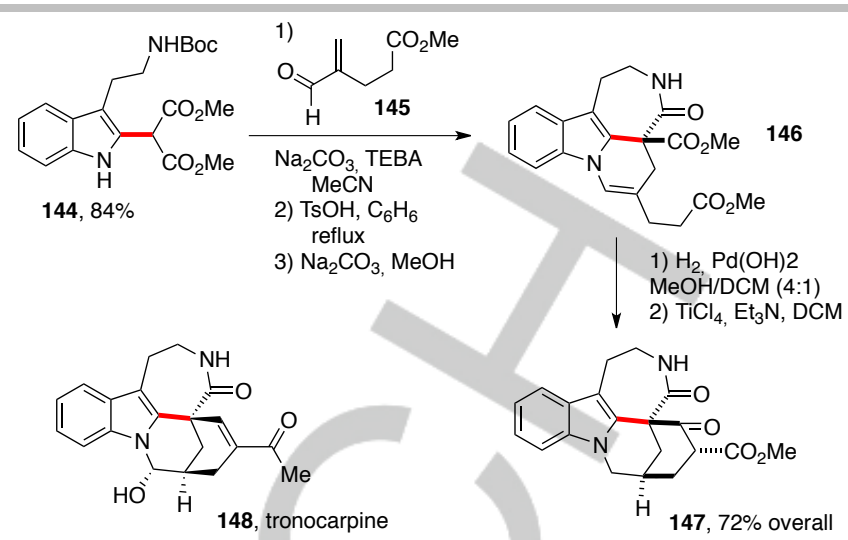

Scheme 31. Model Sequence for the Total Synthesis of Tronocarpine.

\section{Concluding Remarks}

The myriad examples of indolines, indoles, and their aza analogues described in the present review reflect the unique ability of xanthate chemistry to mediate both intermolecular radical additions to electronically unbiased alkenes and cyclizations onto aromatic rings. It even allows intermolecular additions in the case of certain heteroaromatic rings. Various other kinetically relatively slow radical transformations, such as hydrogen atom abstraction and ring opening of cyclobutanes, also succumb to this method but have not yet been exploited in the present context. From the perspective of medicinal chemistry, the enabling features of xanthates opens up numerous opportunities for the expedient synthesis of novel, highly functional scaffolds not readily available otherwise. Medicinal chemists are equally fond of small building blocks that can be conveniently attached to other structures of interest. Indoles 151 and indole-3carboxaldehydes 152 bearing a chloride, a bromide, or a triflate on C-2 are often obtained in one step from the corresponding oxindole 150 (by the action of Vilsmeir salts in the case of aldehydes 152) and engaged in many transition metal catalyzed coupling reactions (Scheme 32). ${ }^{[68]}$ Such oxindoles and azaoxindoles 150 are easily obtained from xanthates 149, themselves derived from anilines and aminopyridines. ${ }^{[33,69]}$ Access to a large variety of 2-halo- and 2-trifluorsulfonyloxyindoles 151 and indole-3-carboxaldehydes 152 becomes thus very simple.

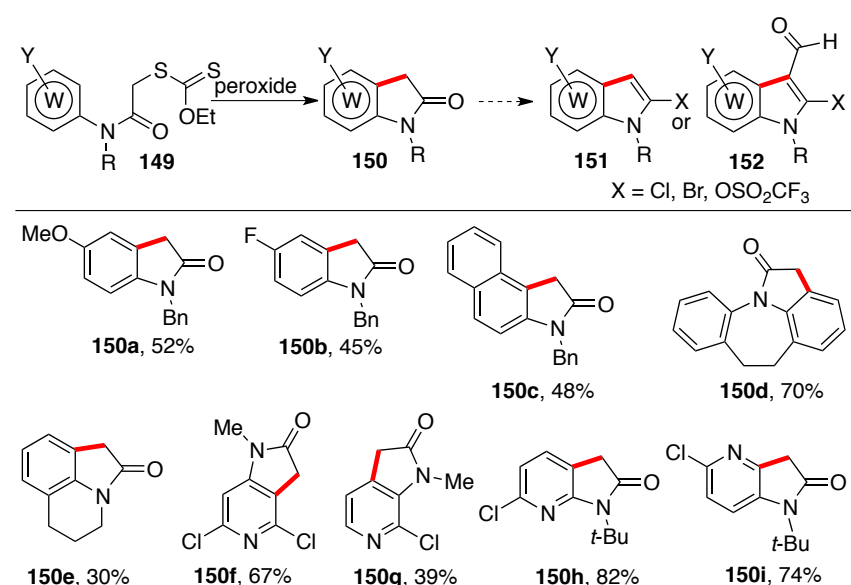


Scheme 32. Synthesis of Oxindoles and Azaoxindoles.

A few examples of oxindoles and azaoxindoles 150a-i are collected in Scheme 32. The synthesis of azaoxindoles 150f-i highlights one important advantage of using a radical based approach, namely the compatibility with electron-deficient heteroaromatics such as pyridines ${ }^{[33]}$ where classical methods for oxindole synthesis (e. g., the Stollé and Hinsberg reactions) give poor results and often fail completely. ${ }^{[4]}$

Finally, the radical addition of xanthates can be used to expand the pool of starting materials for other more established routes to indolines and indoles. For example, a broad variety of ketones and aldehydes can be prepared through radical addition of the appropriate xanthate and used in combination with the famous Fischer indole synthesis. In this respect, it is worth pointing to the fact that the addition of xanthates to vinyl esters and enamides, gives rise to adducts that are in fact masked aldehydes. ${ }^{[70]}$ This is illustrated by the addition of tetralone derived xanthate 153 to vinyl pivalate $(\mathrm{OPiv}=$ pivalate $)$, which furnishes adduct 154, a latent equivalent of 1,4-keto-aldehyde $155 .^{[71]}$ Heating with 2furylamine results in the direct formation of the corresponding pyrrole 156, without need for the prior generation of intermediate 1,4-keto-aldehyde 155. This sequence can be viewed as a convenient variant on the venerable Paal-Knorr pyrrole synthesis (Scheme 32). Furthermore, pyrrole 156, is fused to a cyclohexane motif and could in principle be dehydrogenated into the corresponding indole $157 .^{[1]}$

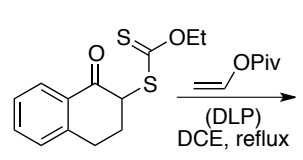

153
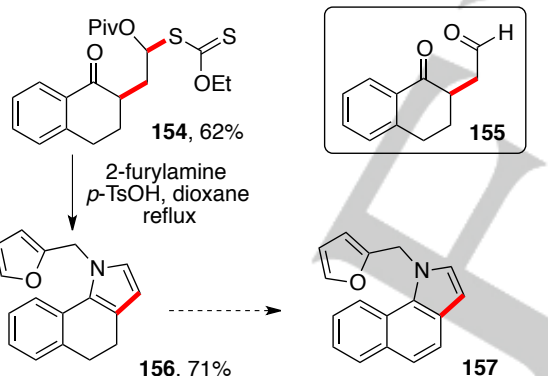

157
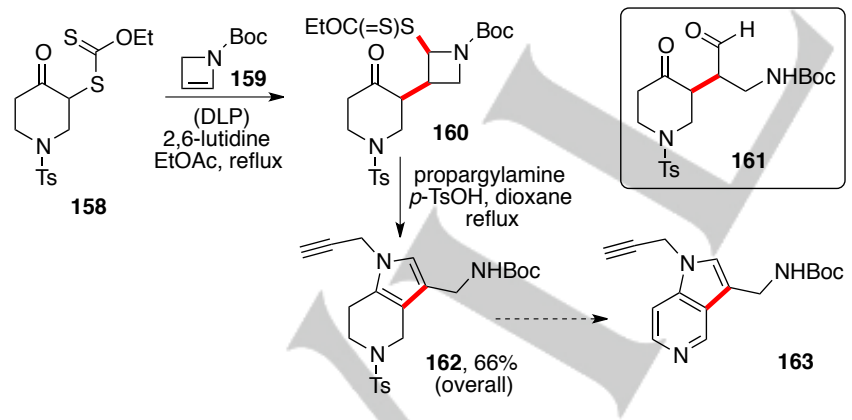

Scheme 33. A Potential Convergent Route to Indoles and Azaindoles.

In a similar manner, xanthate 158 undergoes addition to azetine 159 to give compound 160 , a masked, compact form of 1,4ketoaldehyde $161 .{ }^{[72]}$ Treatment with propargylamine under acid catalysis affords the corresponding pyrrole 162, which could in principle be dehydrogenated into azaindole 163 . The addition of 2,6-lutidine in the radical addition step is to protect azetine 159 against cleavage by adventitious acid. This potential indirect route to indoles and azaindoles complements the above methods and could even prove superior in certain particular cases.

Applications of the present radical chemistry of xanthates to the total synthesis of complex indole alkaloids remain few in number but will certainly increase in the future, when its potential for the simplification of the retrosynthetic schemes becomes more widely appreciated. Indeed, much remains to be done.

\section{Acknowledgements}

I am most grateful to my collaborators, whose names appear in the references, and who contributed decisively to the success of this chemistry. I am especially indebted to Dr Béatrice Sire, who was a key player in many projects over a quarter of a century. I also thank the following organizations and laboratories who have provided financial support over the years: Ecole Polytechnique, CNRS, DGA, MNRT, the Royal Commission for the Exhibition of 1851, the China Research Council, Aventis (now Sanofi), Rhodia (now Solvay), Laboratoires Servier, and Syngenta.

Keywords: indoles • indolines • azaindoles • fluoroazaindoles • radicals

[1] a) G. W. Gribble, Indole Ring Synthesis: From Natural Products to Drug Discovery, John Wiley \& Sons, 2016; b) Heterocyclic Scaffolds II: Reactions and Applications of Indoles, (Ed.: G.W. Gribble), SpringerVerlag, Heidelberg, 2010; c) A. R. Katrizky, C. A. Ramsden, E. F. V. Scriven, R. J. K. Taylor, Comprehensive Heterocyclic Chemistry III, Elsevier, Oxford, 2008.

[2] Dictionary of the Alkaloids, (Eds.: J. Buckingham, K. H. Baggaley, A. D. Roberts, L. F. Szabó), CRC Press, Boca Raton, FL, 2010.

[3] N. K. Kaushik, N. Kaushik, P. Attri, N. Kumar, C. H. Kim, A. K. Verma, E. H. Choi, Molecules 2013, 18, 6620-6662.

[4] a) G. R. Humphrey, J. T. Kuethe, Chem. Rev. 2006, 106, 2875-2911; b) Name reactions in Heterocyclic Chemistry, Vol. 1\&2 (Ed.: J. J. Li), John Wiley \& Sons, Hoboken, NJ, 2005.

[5] See for example: a) M. Inman, C. J. Moody, Chem. Sci. 2013, 4, 29-41; b) M. Inman, C. J. Moody, Chem. Commun. 2011, 47, 788-790; c) K. Hisler, A. G. J. Commeureuc, S. Zhou, J. A. Murphy, Tetrahedron Lett. 2009, 50,3290-3293; d) S. Wagaw, B. H. Yang, S. L. Buchwald, J. Am. Chem. Soc. 1999, 121, 10251-10263.

[6] a) M. Yan, J. C. Lo, J. T. Edwards, P. S. Baran, J. Am. Chem. Soc. 2016, 138, 12692-12714; b) L. Furst, B. S. Matsuura, J. M. R. Narayanam, J. W. Tucker, C. R. J. Stephenson, Org. Lett. 2010, 12, 3104-3107; c) S. Cacchi, G. Fabrizi, Chem. Rev. 2005, 105, 2873-2920.

[7] a) F. Popowycz, J.-Y. Mérour, B. Joseph, Tetrahedron 2007, 63, 86898707 ; b) F. Popowycz, S. Routier, B. Joseph, J.-Y. Mérour, Tetrahedron 2007, 63,1031-1064; c) J. J. Song, J. T. Reeves, F. Gallou, Z. Tan, N. K. Yee, C. H. Senanayake, Chem. Soc. Rev. 2007, 36, 1120-1132.

[8] For reviews, see: a) B. Quiclet-Sire, S. Z. Zard, Isr. J. Chem. 2017, 57, 202-217; b) B. Quiclet-Sire, S. Z. Zard, Pure Appl. Chem. 2010, 83, 519551 ; c) B. Quiclet-Sire, S. Z. Zard, Top Curr. Chem. 2006, 264, 201-236; For an account of the discovery of this process, see: d) S. Z. Zard, Aust. J. Chem. 2006, 59, 663-668; e) S. W. McCombie, B. Quiclet-Sire, S. Z. Zard, Tetrahedron 2018, 74, 4969-4979.

[9] a) S. Z. Zard, J. Phys. Org. Chem. 2012, 25, 953-964; b) S. Z. Zard, Helv. Chim. Acta 2019, 102, e1900134 (10.1002/hlca.201900134).

[10] a) F. LeStrat, J. A. Murphy, M. Hughes, Org. Lett. 2002, 4, 2735-2738; b) C. G. Martin, J. A. Murphy, C. R. Smith, Tetrahedron Lett. 2000, 41, 1833- 1836; c) J. A. Murphy, K. A. Scott, R. S. Sinclair, C. Gonzalez Martin, A. R. Kennedy, N. Lewis, J. Chem. Soc., Perkin Trans. 1, 2000, 2395-2408; d) G. F. Meijs, A. L. J. Beckwith, J. Am. Chem. Soc.1986, 108, 5890-5893; f) A. N. Abeywickrema, A. L. J. Beckwith, J. Am. Chem. Soc. 1986, 108, 8227-8229. 
[11] L. Tournier, S. Z. Zard, Tetrahedron Lett. 2005, 46, 971-973.

[12] Newcomb, M. Tetrahedron 1993, 49, 1151-1176.

[13] a) A. Gansäuer, M. Seddiqzai, T. Dahmen, R. Sure, S. Grimme, Beil. J. Org. Chem. 2013, 9, 1620-1629; b) see also: P. Wipf, J. P. Maciejewski, Org. Lett. 2008, 10, 4383-4386.

[14] T.-M. Ly, B. Quiclet-Sire, B. Sortais, S. Z. Zard, Tetrahedron Lett. 1999, 40, 2533-2536.

[15] S. K. Bagal, L. Tournier, S. Z. Zard, Synlett 2006, 1485-1490.

[16] F. Gagosz, S. Z. Zard, Synlett 2003, 387-389.

[17] F. Bertrand, V. Pevere, B. Quiclet-Sire, S. Z. Zard, Org. Lett. 2001, 3 1069-1071.

[18] D. Clemente-Tejeda, S. Z. Zard, Synlett 2016, 27, 136-140

[19] B. Quiclet-Sire, S. Z. Zard, Org. Lett. 2008, 10, 3279-3282.

[20] B. Quiclet-Sire, G. Revol, S. Z. Zard, Org. Lett. 2009, 11, 3554-3557.

[21] F. Gagosz, S. Z. Zard, Org. Lett. 2003, 5, 2655-2657.

[22] S. Han, S. Z. Zard, Org. Lett. 2014, 16, 5386-5389.

[23] M. De Greef, S. Z. Zard, Tetrahedron 2004, 60, 7781-7791.

[24] S. K. Bagal, M. De Greef, S. Z. Zard, Org. Lett. 2006, 8, 147-150.

[25] B. Hawkins, V. L. Paddock, N. Tölle, S. Z. Zard, Org. Lett. 2012, 14, 1020-1023.

[26] B. M. Trost, T. N. Salzmann, K. Hiroi, J. Am. Chem. Soc. 1976, 98, $4887-$ 4902

[27] C. Mougin, J. Sançon, S. Z. Zard, Heterocycles 2007, 74, 211-218.

[28] B. Sortais, PhD thesis, Ecole Polytechnique, 2002.

[29] M.-P. Denieul, B. Quiclet-Sire, S. Z. Zard, Chem. Commun. 1996, 2511 2512

[30] For a review on the synthesis of organofluorine derivatives using xanthate chemistry, see: S. Z. Zard, Org. Biomol. Chem. 2016, 14, 68916912.

[31] F. Coppa, F. Fontana, F. Minisci, G. Pianese, P. Tortoreto, L. Zhao, Tetrahedron Lett. 1992, 33, 687-690.

[32] a) M. Jeanty, J. Blu, F. Suzenet, G. Guillaumet Org. Lett., 2009, 11, 51425145 and references therein; b) Crooks, P. A.; Robinson, B. Can. J. Chem. 1969, 47, 2061-2067.

[33] a) E. Bacqué, M. El Qacemi, S. Z. Zard, Org. Lett. 2004, 6, 3671-3674 b) E. Bacqué, M. EI Qacemi, S. Z. Zard, Heterocycles 2012, 84, 291-299.

[34] Y. Laot, L. Petit, S. Z. Zard, Chem. Commun. 2010, 46, 5784-5786.

[35] M. A. J. Duncton, Med. Chem. Commun. 2011, 2, 1135-1161.

[36] P. Salomon, W. Kosnik, S. Z. Zard, Tetrahedron 2015, 71, 7144-7153.

[37] L. El Kaïm, L. Grimaud, P. Pravin, Molecules 2011, 16, 9261-9273.

[38] a) L. El Kaim, L. Grimaud, J. Oble, Angew. Chem. Int. Ed. 2005, 44 7961-7964; b) L. El Kaim, M. Gizolme, L. Grimaud, J. Oble, Org. Lett. 2006, 8, 4019-4021; c) L. El Kaim, M. Gizolme, L. Grimaud, J. Oble, J. Org. Chem. 2007, 72, 4169-4180.

[39] C. Moutrille, S. Z. Zard, Tetrahedron Lett. 2004, 45, 4631-4634.

[40] a) M. P. Cava, A. A. Deano, J. Am. Chem. Soc. 1959, 81, 4266-4267; b) K. Wojciechowski, Synlett 1991, 571-572; c) K. Wojciechowski, Eur. J. Org. Chem. 2001, 3587-3605.

[41] G. Sandford in Halogenated Heterocycles: Synthesis, Application and Environment, (Ed.: J. Iskra), Springer, Berlin, Heidelberg, 2012; pp 1-31; b) H. Amii, K. Uneyama, Chem. Rev. 2009, 109, 2119-2183; c) C. A Hargreaves, G. Sanford, R. Slater, D. S. Yufit, J. A. K. Howard, A. Vong, Tetrahedron 2007, 63, 5204-5211.

[42] Y. Laot, L. Petit, S. Z. Zard, Org. Lett. 2010, 12, 3426-3429.

[43] Y. Laot, L. Petit, N. D. M. Tran, S. Z. Zard, Aust. J. Chem. 2011, 64, 416425.

[44] Z. Liu, L. Qin, S. Z. Zard, Org. Lett. 2014, 16, 2704-2707.

[45] K. C. Nicolaou, C. J. N. Mathison, T. Montagnon, J. Am. Chem. Soc. 2004, 126, 5192-5201.

[46] a) F. Peng, M. McLaughlin, Y. Liu, I. Mangion, D. M. Tschaen, Y. Xu, J Org. Chem. 2016, 81, 10009-10015; b) U. Tilstam, M. Harre, T. Heckrodt, H. Weinmann, Tetrahedron Lett. 2001, 42, 5385-5387; c) I. Ninomiya, T. Kiguchi, C. Hashimoto, D. H.R. Barton, X. Lusinchi, P. Milliet, Tetrahedron Lett. 1985, 26, 4183-4186; d) A. B. A. Jansen, J. M. Johnson, J. R. Surtees, J. Chem. Soc. 1964, 5573-5577. See also ref. 1a.

[47] P. Salomon, S. Z. Zard, Org. Lett. 2014, 16, 2926-2929.

[48] H. Rueeger, R. Lueoend, O. Rogel, J.-M. Rondeau, H. Möbitz, R. Machauer, L. Jacobson, M. Staufenbiel, S. Desrayaud, U. Neumann, J. Med. Chem. 2012, 55, 3364-3386.
[49] B. Quiclet-Sire, B. Sortais, S. Z. Zard, Chem. Commun. 2002, 16921693.

[50] a) T. Shiori, K. Ninomiya, S. Yamada, J. Am. Chem. Soc. 1972, 94, 62036205; b) P. A. S. Smith, Org. React., 1946, 3, 337-349.

[51] M. Boumédienne, PhD thesis, Ecole Polytechnique, 2011.

[52] E. Tate, S. Z. Zard, Tetrahedron Lett. 2002, 43, 4683-4686.

[53] T. Kaoudi, B. Quiclet-Sire, S. Seguin, S. Z. Zard, Angew. Chem. Int. Ed. Engl. 2000, 39, 731-733.

[54] a) A. Rentería-Gómez, A. Islas-Jácome, E. Díaz-Cervantes, T. Villaseñor-Granados, J. Robles, R. Gámez-Montaño, Bioorg. Med. Chem. Lett. 2016, 26, 2333-2338; b) R. E. Gordillo-Cruz, A. RenteríaGómez, A. Islas-Jácome, C. J. Cortes-García, E. Díaz-Cervantes, J. Robles, R. Gámez-Montaño, Org. Biomol. Chem. 2013, 11, 6470-6476.

[55] A. Biéchy, S. Z. Zard, Org. Lett. 2009, 11, 2800-2803.

[56] J. Magolan, C. A. Carson, M. A. Kerr, Org. Lett. 2008, 10, 1437-1440.

[57] Y. M. Osornio, R. Cruz-Almanza, V. Jiménez-Montaño, L. D. Miranda, Chem. Commun. 2003, 2316-2317.

[58] a) P. López-Mendoza, J. E. Díaz, A. E. Loaiza, L. D. Miranda, Tetrahedron, 2018, 74, 5494-5502; b) P. E. Reyes-Gutiérrez, R. O Torres-Ochoa, R. Martínez, L. D. Miranda, Org. Biomol. Chem., 2009, 7 , 1388-1396.

[59] M.-G. Braun, G. Castanedo, L. Qin, P. Salvo, S. Z. Zard, Org. Lett. 2017, 19, 4090-4093.

[60] B. Quiclet-Sire, S. Z. Zard, Heterocycles 2010, 82, 263-271.

[61] S. Han, S. Z. Zard, Tetrahedron 2015, 71, 3680-3689.

[62] a) C. I. Canché Chay, R. Gómez Cansino, C. I. Espitia Pinzón, R. O. Torres-Ochoa, R. Martínez, Mar. Drugs 2014, 12, 1757-1772. See also: b) H. Li, X. Liao, Y. Sun, R. Zhou, W. Long, L. Li, L. Gu, S. Xu, ChemistrySelect 2018, 3, 12406-12409.

[63] N. A. Meanwell, J. Med. Chem. 2011, 54, 2529-2591.

[64] E. M. Carreira, T. C. Fessard, Chem. Rev. 2014, 114, 8257-8322.

[65] V. L. Revil-Baudard, J.-P. Vors, S. Z. Zard, Org. Lett. 2018, 20, 35313535.

[66] Q. Huang, S. Z. Zard, Org. Lett. 2018, 20, 1413-1416.

[67] R. O. Torres-Ochoa, P. E. Reyes-Gutiérrez, R. Martínez, Eur. J. Org. Chem. 2014, 48-52.

[68] For selected examples, see: a) N. J. Race, Q. Yuan, M. S. Sigman, Chem. Eur. J. 2019, 25, 512-515; b) Z. Xie, Y. Zhou, W. Zhao, H. Jiao, Y. Chen, Y. Yang, Z. Li, Bioorg. Med. Chem. Lett. 2015, 25, 4557-4561; c) G. lakobson, M. Pošta, P. Beier, Synlett 2013, 24, 855-859; d) B. Liégault, I. Petrov, S. I. Gorelsky, Keith Fagnou, J. Org. Chem. 2010, 75, 10471060; e) A. N. C. Lötter, R. Pathak, T. S. Sello, M. A. Fernandes, W. A. L. van Otterlo, C. B. de Koning, Tetrahedron 2007, 63, 2263-2274; f) E. Rossi, G. Abbiati, V. Canevari, G. Celentano, E. Magri, Synthesis 2006, 299-304; g) J. J. Chen, Y. Wei, J. C. Drach, L. B. Townsend, J. Med. Chem. 2000, 43, 2449-2456; h) F. Chan, P. Magnus, E. G. Mclver, Tetrahedron Lett. 2000, 41, 835-838.

[69] a) J. Axon, L. Boiteau, J. Boivin, J. E. Forbes, S. Z. Zard, Tetrahedron Lett. 1994, 35, 1719-1722; see also: b) S. Wang, X. Huang, Y. Wen, Z. Ge, X. Wang, R. Li, Tetrahedron 2015, 71, 8117-8122.

[70] B. Quiclet-Sire, S. Z. Zard, Heterocycles 2019, 99, 742-765.

[71] B. Quiclet-Sire, L. Quintero, G. Sanchez-Jimenez, S. Z. Zard, Synlett 2003, 75-78.

[72] S. Han, S. Z. Zard, Org. Lett. 2014, 16, 1992-1995. 


\section{Entry for the Table of Contents}

Insert graphic for Table of Contents here.

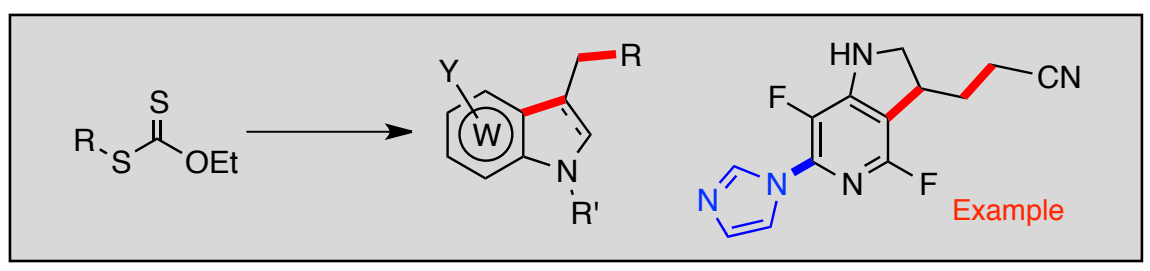

Text for Table of Contents. Fast and cheap paths to indoles and friends. Xanthates provide multiple convergent radical-based routes to indoles, indolines, oxindoles, and their aza analogues including fluorinated derivatives. Numerous otherwise inaccessible structures can now be obtained quickly using inexpensive, metal-free reagents. 